\title{
Spatial distribution of turbulent mixing in the upper ocean of the South China Sea
}

\author{
Xiao-Dong Shang ${ }^{1}$, Chang-Rong Liang ${ }^{1,2}$, and Gui-Ying Chen ${ }^{1}$ \\ ${ }^{1}$ State Key Laboratory of Tropical Oceanography, South China Sea Institute of Oceanology, Chinese Academy \\ of Sciences, Guangzhou 510301, China \\ ${ }^{2}$ University of Chinese Academy of Sciences, Beijing 100049, China \\ Correspondence to: Xiao-Dong Shang (xdshang@scsio.ac.cn)
}

Received: 30 September 2016 - Discussion started: 11 November 2016

Revised: 8 May 2017 - Accepted: 16 May 2017 - Published: 26 June 2017

\begin{abstract}
The spatial distribution of the dissipation rate $(\varepsilon)$ and diapycnal diffusivity $(\kappa)$ in the upper ocean of the South China Sea (SCS) is presented from a measurement program conducted from 26 April to 23 May 2010. In the vertical distribution, the dissipation rates below the surface mixed layer were predominantly high in the thermocline where shear and stratification were strong. In the regional distribution, high dissipation rates and diapycnal diffusivities were observed in the region to the west of the Luzon Strait, with an average dissipation rate and diapycnal diffusivity of $8.3 \times 10^{-9} \mathrm{~W} \mathrm{~kg}^{-1}$ and $2.7 \times 10^{-5} \mathrm{~m}^{2} \mathrm{~s}^{-1}$, respectively, almost 1 order of magnitude higher than those in the central and southern SCS. In the region to the west of the Luzon Strait, the water column was characterized by strong shear and weak stratification. Elevated dissipation rates $\left(\varepsilon>10^{-7} \mathrm{~W} \mathrm{~kg}^{-1}\right)$ and diapycnal diffusivities $\left(\kappa>10^{-4} \mathrm{~m}^{2} \mathrm{~s}^{-1}\right)$, induced by shear instability, occurred in the water column. In the central and southern SCS, the water column was characterized by strong stratification and weak shear and the turbulent mixing was weak. Internal waves and internal tides generated near the Luzon Strait are expected to make a dominant contribution to the strong turbulent mixing and shear in the region to the west of the Luzon Strait. The observed dissipation rates were found to scale positively with the shear and stratification, which were consistent with the MacKinnon-Gregg model used for the continental shelf but different from the Gregg-Henyey scaling used for the open ocean.
\end{abstract}

\section{Introduction}

Turbulent mixing is a crucial mechanism that controls the distribution of nutrients, sediments, freshwater, and pollutants throughout the water column (Sandstrom and Elliott, 1984). The magnitude and distribution of diapycnal diffusivity are important for large-scale ocean circulation (Saenko and Merryfield, 2005). Assuming a balance between vertical advection and vertical diffusion for tracers, Munk (1966) reported that a global average diapycnal diffusivity of $10^{-4} \mathrm{~m}^{2} \mathrm{~s}^{-1}$ is required to maintain gross oceanic stratification and overturning circulation (Tsujino et al., 2000). However, diapycnal diffusivity from turbulent mixing in the open ocean thermocline only ranges from $5 \times 10^{-6}$ to $3 \times 10^{-5} \mathrm{~m}^{2} \mathrm{~s}^{-1}$ (Gregg, 1998; Polzin et al., 1995). Therefore, it has been argued that elevated turbulent mixing concentrated over rough topography (Ledwell et al., 2000; Wu et al., 2011) would aid in explaining this discrepancy. In the past decade, elevated diapycnal diffusivities, i.e., $O\left(10^{-4} \mathrm{~m}^{2} \mathrm{~s}^{-1}\right)$ or higher, have been found in mixing hotspots such as seamounts (Carter et al., 2006; Lueck and Mudge, 1997), ridges (Klymak et al., 2006a; Lee et al., 2006), and canyons (Carter and Gregg, 2002). However, these elevated mixing events are highly localized. Whether such topographically enhanced mixing is sufficiently intense or widespread to significantly increase the basin-wide average remains unclear. Using a simple averaging scheme, Kunze and Toole (1997) suggested that topographically induced mixing was insufficient to support a basin-averaged diffusivity of $O\left(10^{-4} \mathrm{~m}^{2} \mathrm{~s}^{-1}\right)$ above a $3000 \mathrm{~m}$ depth in the North Pacific. 
Compared with the open ocean, less attention has been given to marginal seas. In recent years, observations (Tian et al., 2009) indicated that turbulent mixing in marginal seas could make an important contribution to ocean mixing. The South China Sea (SCS), one of the largest marginal seas of the Pacific, connects to the Pacific through the Luzon Strait. Measurements and numerical simulations (Alford et al., 2015; Chang et al., 2006; Lien et al., 2005) indicated that energetic internal tides and internal waves generated near the Luzon Strait propagate into the SCS and facilitate turbulent mixing. Considerable effort has been put forth to explore the characteristics of turbulent mixing in the SCS. Using fine-scale parameterization, Tian et al. (2009) reported a turbulent mixing distribution along a section from the northern SCS to the Pacific. They found that the diapycnal diffusivity in the upper $500 \mathrm{~m}$ of the northern SCS reached $O\left(10^{-5} \mathrm{~m}^{2} \mathrm{~s}^{-1}\right)$, almost 1 order of magnitude larger than that in the Pacific. Yang et al. (2016) explored the turbulent mixing in the SCS with a fine-scale parameterization and found diapycnal diffusivity in the northern SCS as large as $O\left(10^{-3} \mathrm{~m}^{2} \mathrm{~s}^{-1}\right)$. In addition to these parameterizations, some direct measurements from microstructure profilers are also available. A direct observation of turbulent dissipation was reported by Laurent (2008), who found a dissipation rate as high as $10^{-6} \mathrm{~W} \mathrm{~kg}^{-1}$ over the shelf break of the northern SCS. Lozovatsky et al. (2013) reported a regional mapping of the averaged dissipation rate in the upper pycnocline of the northern SCS and found values in the Luzon Strait as high as $10^{-7} \mathrm{~W} \mathrm{~kg}^{-1}$. Yang et al. (2014) conducted direct measurements of turbulence along a section across the continental shelf and slope in the northern SCS. Their results show that the averaged dissipation rate over the shelf reached $10^{-7} \mathrm{~W} \mathrm{~kg}^{-1}$, which is an order of magnitude larger than that over the slope. There is no doubt that these studies have greatly aided our knowledge of turbulent mixing in the SCS. However, the direct microstructure measurements are localized and scattered, with most of them focusing on the northern SCS. Few microstructure measurements have been conducted in the central and southern SCS. Where the strong turbulent mixing takes place in the SCS and what drives the turbulent mixing are not fully understood. In this work, we present direct microstructure measurements that cover the upper ocean of the SCS and explore the features and regimes of the turbulent mixing. Energy sources for the turbulent mixing are also discussed.

In addition, there is a lack of studies assessing parameterizations in the SCS. Fine-scale parameterizations are aimed at reproducing the dissipation rate in terms of more easily observed or modeled quantities, such as stratification and shear. Generally, microstructure measurements are fewer and more difficult than the fine-structure measurements (e.g., CTD and ADCP measurements), especially microstructure measurements in the deep sea. Therefore, to study the spatial and temporal distribution of turbulent mixing, researchers often resort to fine-scale parameterizations (Jing and Wu, 2010; Tian et al., 2009; Wu et al., 2011). In addition, fine-scale parameterizations would provide a reference for modelers. Shelf sea models have success in reproducing the water column structure in seasonally stratified shelf seas (Holt and Umlauf, 2008; Simpson and Bowers, 1981). However, models need to calibrate a background mixing level to correctly predict the water column structure (Rippeth, 2005). The requirement of calibration reduces the success of models on shelfwide scales since differing forcing mechanisms and mixing processes require specific methods and levels of tuning. This presents a clear challenge to oceanographic models. Before the water column structure in shelf seas can be modeled realistically, the distribution of mixing must be established and the major mixing processes parameterized. Confidence in future predictions is therefore dependent on an ocean turbulence model that can be validated against observed mixing or parameterized mixing, but not on the calibration of a background mixing level. In order to estimate the turbulent mixing without microstructure measurements, we assess two fine-scale parameterizations with microstructure data and investigate which one works better and why it works better. We begin in Sect. 2 with a description of our measurements and methods. In Sect. 3 we explore the features and regimes of the turbulent mixing, and assess two fine-scale parameterizations. We discuss the turbulent mixing and fine-scale parameterizations in Sect. 4. A summary of our results is presented in Sect. 5.

\section{Measurements and methods}

The field experiment was performed from 26 April to 23 May 2010 (local time) prior to the South China Sea summer monsoon (SCSSM) onset. A total of 82 stations were conducted in the experiment (Fig. 1a). Direct turbulence measurements were collected with the Turbulence Ocean Microstructure Acquisition Profiler (TurboMAP). TurboMAP is a quasi-free-falling instrument that measures turbulent parameters $(\partial u / \partial z$ and $\partial T / \partial z)$, bio-optical parameters (in vivo fluorescence and backscatter), and hydrographic parameters (conductivity, temperature, and depth; Wolk et al., 2002). TurboMAP carries seven environmental sensors and a threeaxis accelerometer that measures tilt and vibrations. The turbulent velocity fluctuations are measured with two standard shear probes. Conductivity $(C)$ and temperature $(T)$ are measured with a combined $C-T$ sensor consisting of a platinum wire thermometer and an inductive conductivity cell. Depth is measured with a semiconductor strain gauge pressure transducer, and the instrument's sinking velocity is computed from the rate of change of the pressure signal. All sensors are sampled at a rate of $256 \mathrm{~Hz}$. TurboMAP was deployed at a speed of $0.5-0.7 \mathrm{~m} \mathrm{~s}^{-1}$ and the maximum deployment depth was approximately $800 \mathrm{~m}$. It took $10-30 \mathrm{~min}$ to complete each profile at shallow stations and approximately $1 \mathrm{~h}$ at deep stations. Continuous time series of velocity at 
$5 \mathrm{~min}$ intervals and $16 \mathrm{~m}$ vertical spacing between 38 and $982 \mathrm{~m}$ were obtained from a shipboard acoustic Doppler current profiler (ADCP). At stations where the water depth was more than $982 \mathrm{~m}$, the current velocity cannot be referenced to the sea floor. The movement of the ship was determined from GPS data and absolute value of current velocity was estimated. CTD casts were conducted to provide measurements of temperature and salinity for comparison. At stations where the water depth was less than $800 \mathrm{~m}$, CTD was deployed to $5 \mathrm{~m}$ above the seafloor. At stations where the water depth was larger than $800 \mathrm{~m}$, the maximum deployment depth of CTD ranged from 800 to $1500 \mathrm{~m}$. Data obtained from six moorings (Fig. 1, yellow squares) were used to perform a brief analysis of the internal wave field in the SCS. Moorings 1-3 were deployed over the continental shelf/slope and moorings 4-6 were deployed in the deep basin. More information regarding the moorings is given in Table 1 .

Figure $2 \mathrm{a}$ shows the depth profile of shear $\partial u / \partial z$. At depths of 190-200 m, the shear signal shows variations with peak levels around $0.6 \mathrm{~s}^{-1}$, corresponding to dissipation rates of $10^{-7} \mathrm{~W} \mathrm{~kg}^{-1}$. The velocity shear decreases below $200 \mathrm{~m}$ to peak values of $0.02 \mathrm{~s}^{-1}$, corresponding to dissipation rates of $10^{-10} \mathrm{~W} \mathrm{~kg}^{-1}$. Dissipation spectra $\psi(k)$ computed from the shear signal in Fig. $2 \mathrm{a}$ are shown in Fig. 2b-g along with the corresponding scaled Nasmyth universal spectra (Nasmyth, 1970). The shape of the measured spectra agrees well with the universal spectrum except in the wavenumber regions affected by vibration noise caused by the strumming of the suspension wires in the flow (Wolk et al., 2002). The spectra are computed using Welch's averaged periodogram method with a fast Fourier transformation (FFT) length of $2 \mathrm{~m}$, corresponding to a consecutive segment of approximately 1700 data points. The dissipation rates $\varepsilon$ based on the measured spectra range from $10^{-10}$ to $10^{-7} \mathrm{~W} \mathrm{~kg}^{-1}$, and they are computed by integrating the measured shear spectrum

$\varepsilon=7.5 v\left\langle\left(\frac{\partial u}{\partial z}\right)^{2}\right\rangle=7.5 v \int_{k_{1}}^{k_{2}} \psi(k) \mathrm{d} k$,

where $v$ is the kinematic viscosity and \langle\rangle denotes the spatial average. $k_{1}$ and $k_{2}$ are the integration limits. The lower integration limit $k_{1}$ is set to $1 \mathrm{cpm}$ and the upper limit $k_{2}$ is the highest wavenumber that is not contaminated by vibration noise. Energy density in the low wavenumber area around $1 \mathrm{cpm}$ is not well estimated because of the limited length of the data segments and the length of the profiler itself as the profiler tends to follow the larger-scale flow. The noise level of the TurboMAP profiler is $\varepsilon \sim 10^{-10} \mathrm{~W} \mathrm{~kg}^{-1}$ (Matsuno and Wolk, 2005; Wolk et al., 2002). Diapycnal diffusivity (Osborn, 1980) was calculated based on the dissipation rate $(\varepsilon)$ and stratification $\left(N^{2}=-(g / \rho) \partial \rho / \partial z\right)$ using

$\kappa=\Gamma \varepsilon / N^{2}$, where the mixing efficiency $\Gamma$ is set to 0.2 (Oakey, 1982). The shear variance, $S^{2}=(\Delta \bar{U} / \Delta z)^{2}+(\Delta \bar{V} / \Delta z)^{2}$, was calculated with $\Delta z=16 \mathrm{~m}$, where $\bar{U}$ and $\bar{V}$ are the respective zonal and meridional components of the mean horizontal velocity obtained from the shipboard ADCP. The mean velocity is averaged over the time intervals of the TurboMAP measurements.

\section{Results}

\subsection{Water mass properties}

Intrusion of water from the Pacific can influence the evolving water properties in the SCS. It has been confirmed by in situ measurements and models (Shaw, 1991; Wu and Hsin, 2012) that there is a strong intrusion of water from the Pacific into the SCS through the Luzon Strait. Two well-defined water masses are active in this process (Qu et al., 2000): high-salinity North Pacific Tropical Water (NPTW) and lowsalinity North Pacific Intermediate Water (NPIW). For simplicity, we divide the observations into four regions (Fig. 1): region 1 is located to the west of the Luzon Strait, region 2 is located to the northeast of Hainan Island, region 3 is located in the central SCS, and region 4 is located in the southern SCS. Figure 3 shows the $T-S$ curves of the SCS and western Pacific. Temperature and salinity data in the western Pacific $\left(18.5-22.5^{\circ} \mathrm{N}, 124.5-128.5^{\circ} \mathrm{E}\right)$ were obtained from the World Ocean Database 2013 (http://www.nodc.noaa.gov/ OC5/woa13/woa13data.html). The $T-S$ curve in the western Pacific shows a reversed " $S$ " shape with NPTW and NPIW clearly identified (Fig. 3, black dashed curve). NPTW and NPIW correspond to the maximum salinity layer at $\sigma_{\theta} \in(22.5-25.5) \mathrm{kg} \mathrm{m}^{-3}$ and minimum salinity layer at $\sigma_{\theta} \in$ (25.5-27.5) $\mathrm{kg} \mathrm{m}^{-3}$, respectively. In the maximum salinity layer $\left(22.5-25.5 \mathrm{~kg} \mathrm{~m}^{-3}\right)$, the water column in region 1 had a salinity maximum of 34.8 psu that approaches the maximum value of the NPTW. Salinity decreased gradually from the Luzon Strait to Hainan Island (region 2) and to the central and southern SCS (region 3 and region 4). This trend is reversed in the minimum salinity layer $\left(25.5-27.5 \mathrm{~kg} \mathrm{~m}^{-3}\right)$, where the salinity slightly increased from the Luzon Strait to Hainan Island and to the central and southern SCS. The salinity minimum in the Pacific was found to be lower than that in the SCS. The reverse $\mathrm{S}$ shape becomes remarkably weak from the northern SCS to the southern SCS, a change to which turbulent mixing occurring in the SCS might have made a significant contribution.

\subsection{Microstructure measurements}

Figure 4a shows the distribution of the dissipation rate with the thermocline boundaries overlain. Different criteria have been used to define the top of the thermocline $\left(z_{\mathrm{t}}\right)$ in terms of either temperature or density. Here, we defined the top of the thermocline as the depth at which the potential temperature 

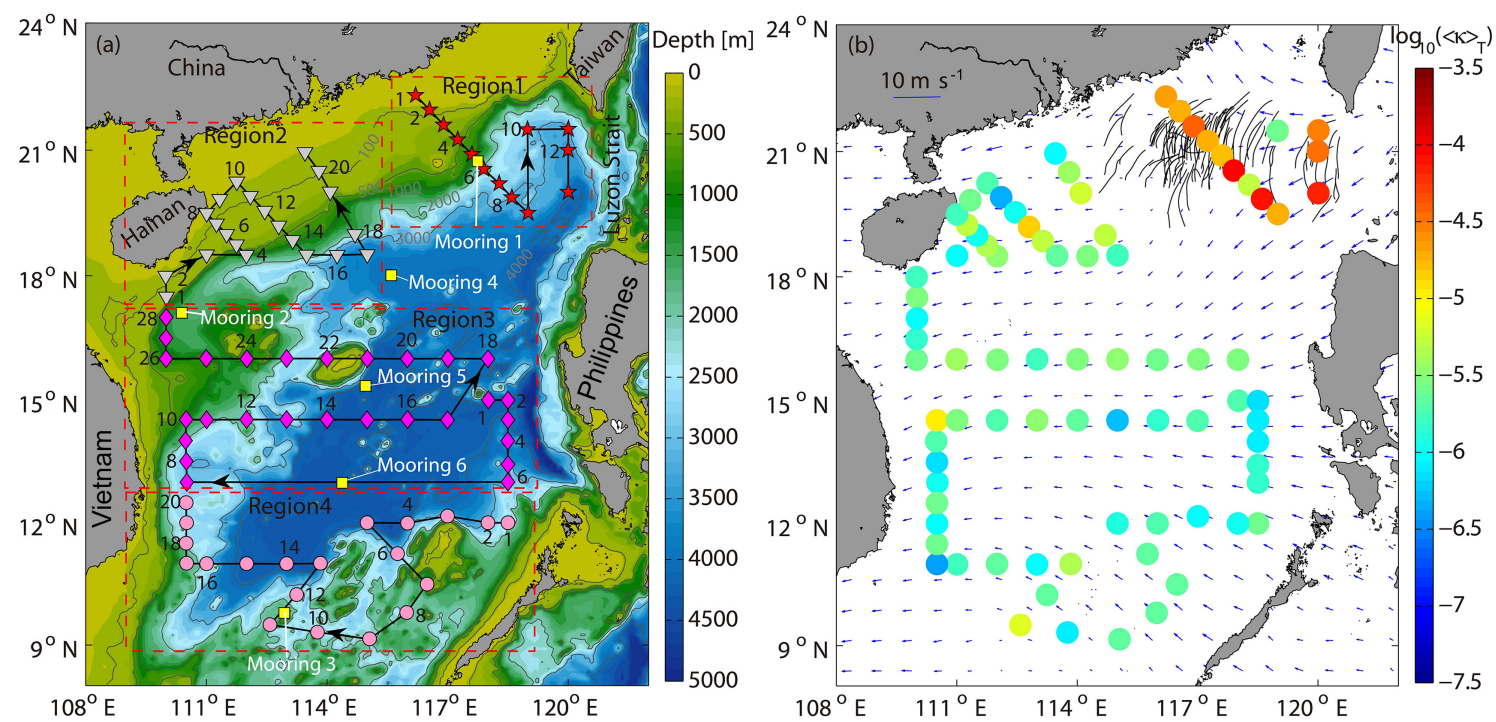

Figure 1. (a) Bottom topography of the SCS and observation stations (symbols). Red stars indicate the stations located in region 1. Gray triangles indicate the stations located in region 2. Magenta diamonds indicate the stations located in region 3. Pink dots indicate the stations located in region 4. Station numbers (i.e., 1, 2, $4 \ldots$ ) are indicated in each region. The arrows indicate the order of the measurement. The yellow squares indicate the locations of the moorings. (b) Spatial distribution of $\langle\kappa\rangle_{\mathrm{T}}$ (color dots). The blue vector gives the averaged $10 \mathrm{~m}$ wind speed during the cruises. Black curves in the northern SCS are internal wave packets derived from satellite images by Zhao et al. (2004).

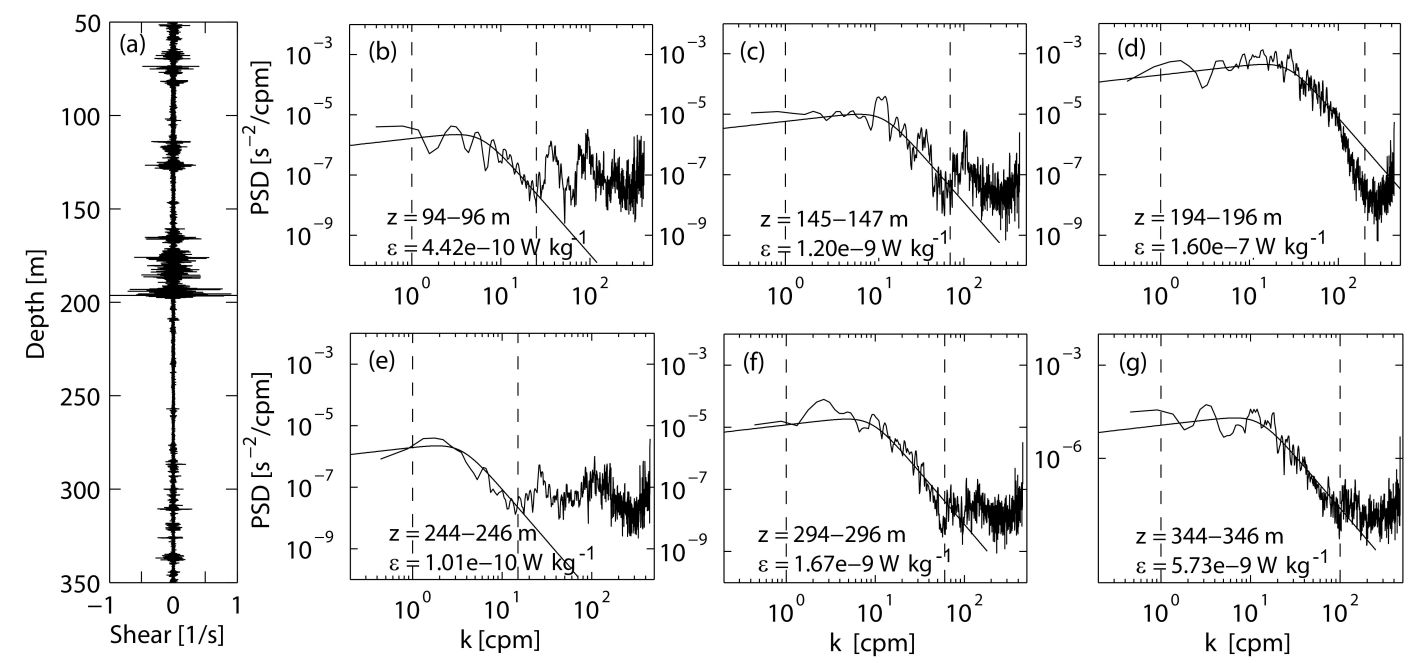

Figure 2. Examples of (a) micro-shear and (b-g) shear spectra at different depths. The integration bounds (vertical dashed lines) and Nasmyth spectra (smooth curves) are shown.

change from the surface temperature is $0.5^{\circ} \mathrm{C}$. The bottom of the thermocline $\left(z_{\mathrm{b}}\right)$ is defined as the depth at which the temperature gradient is equal to $0.05^{\circ} \mathrm{C} \mathrm{m}^{-1}$. The surface mixed layers are slightly deep in region 1 compared with the other regions. The average depths of the surface mixed layer in regions $1-4$ are $35.2,14.7,19.4$, and $26.8 \mathrm{~m}$, respectively.

In the surface mixed layer, strong turbulence was accompanied by high dissipation rates (Fig. 4a), which may be attributed to various factors, such as wind stirring, buoyancy flux, and surface waves. Below the surface mixed layer, high dissipation rates (Fig. 4a) were observed in the ther- mocline, with the average $\varepsilon$ in the thermocline reaching $4.6 \times 10^{-9} \mathrm{~W} \mathrm{~kg}^{-1}$, which was 5 times larger than the value of $8.2 \times 10^{-10} \mathrm{~W} \mathrm{~kg}^{-1}$ below the thermocline. Strong shear (Fig. 4d) also occurred in the thermocline, with an averaged $S^{2}$ in the thermocline of $3.3 \times 10^{-5} \mathrm{~s}^{-2}$, which was 5 times larger than that below the thermocline $\left(6.5 \times 10^{-6} \mathrm{~s}^{-2}\right)$. The strong spatial correlation between dissipation and shear implies that shear played an important role in driving the dissipation. Contrary to the dissipation rates, the diapycnal diffusivities (Fig. 4b) in the thermocline were slightly weaker than that below the thermocline. The high diapycnal diffusiv- 
Table 1. Information about the moorings.

\begin{tabular}{lrrrrrrr}
\hline Mooring & $\begin{array}{r}\text { Latitude } \\
\left({ }^{\circ} \mathrm{N}\right)\end{array}$ & $\begin{array}{r}\text { Longitude } \\
\left({ }^{\circ} \mathrm{E}\right)\end{array}$ & $\begin{array}{r}\text { Water depth } \\
(\mathrm{m})\end{array}$ & $\begin{array}{r}\text { Measurement depth } \\
\text { range }(\mathrm{m})\end{array}$ & $\begin{array}{r}\text { Measurement } \\
\text { duration }(\mathrm{d} / \mathrm{m} / \mathrm{yr})\end{array}$ & $\begin{array}{r}\text { Time interval } \\
(\mathrm{min})\end{array}$ & $\begin{array}{r}\text { Bin size } \\
(\mathrm{m})\end{array}$ \\
\hline Mooring 1 & 20.74 & 117.75 & 1260 & $13-454$ & $01 / 08 / 14-27 / 09 / 14$ & 2 & 16 \\
Mooring 2 & 17.10 & 110.39 & 1410 & $6-478$ & $04 / 05 / 09-04 / 09 / 10$ & 60 & 8 \\
Mooring 3 & 9.79 & 112.74 & 1680 & $40-416$ & $25 / 05 / 09-10 / 11 / 10$ & 60 & 8 \\
Mooring 4 & 18.01 & 115.60 & 3790 & $60-370$ & $09 / 04 / 98-05 / 10 / / 98$ & 60 & 10 \\
Mooring 5 & 15.34 & 114.96 & 4265 & $30-270$ & $07 / 10 / 98-11 / 04 / / 99$ & 60 \\
Mooring 6 & 12.98 & 114.38 & 4370 & $30-270$ & $09 / 10 / 98-12 / 04 / / 99$ & 60 & 10 \\
\hline
\end{tabular}

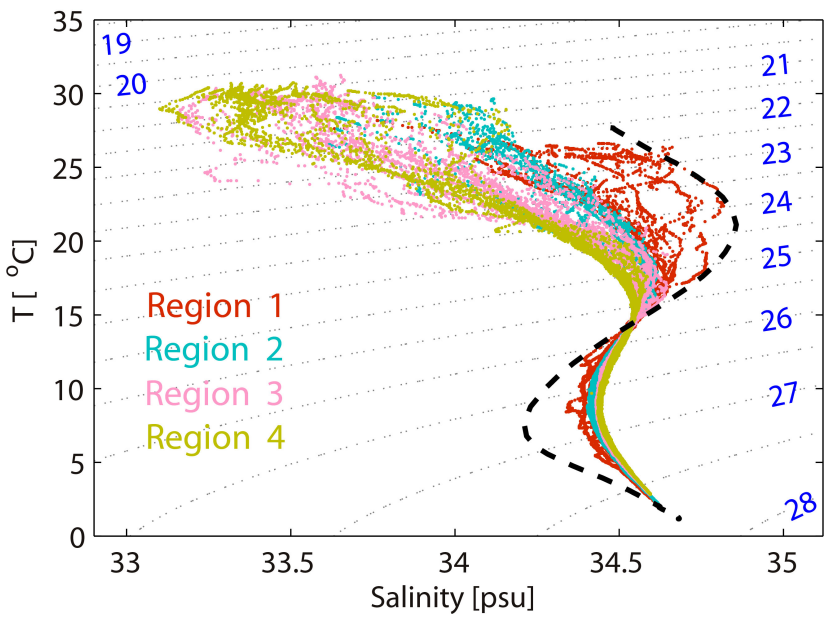

Figure 3. Relation of potential temperature versus salinity (with the potential density $\sigma_{\theta}$ in $\mathrm{kg} \mathrm{m}^{-3}$ contours overlaid) of all stations. The black dashed curve shows the relation for potential temperature versus salinity of the western Pacific for reference.

ities below the thermocline were mainly due to the relatively weak stratification (Fig. 4c). The average $N^{2}$ below the thermocline was $8.4 \times 10^{-5} \mathrm{~s}^{-2}, 4$ times smaller than the value of $3.4 \times 10^{-4} \mathrm{~s}^{-2}$ in the thermocline.

Turbulent mixing in region 1 displayed a different feature from that of the other regions. In region 1, turbulence was more active than that in other regions, with the maximum dissipation rate reaching $10^{-6} \mathrm{~W} \mathrm{~kg}^{-1}$ (Fig. 4a) and the maximum diapycnal diffusivity exceeding $10^{-3} \mathrm{~m}^{2} \mathrm{~s}^{-1}$ (Fig. 4b). In addition, region 1 had weak stratification but strong shear compared with other regions (Fig. 4c and d). Most of the water column in region 1 was occupied by a Richardson number of order 1, almost 2 orders of magnitude smaller than that in the other regions (Fig. 4e). Richardson number $R i=N^{2} / S^{2}$ was estimated following MacKinnon and Gregg (2005). A $2 \mathrm{~m}$ buoyancy frequency and $16 \mathrm{~m}$ shear were used in the calculation. The resolutions of shear used in previous literatures range from $2 \mathrm{~m}$ to $16 \mathrm{~m}$ (MacKinnon and Gregg, 2003b, 2005; van der Lee and Umlauf, 2011; Xie et al., 2013; Yang et al., 2014). High resolution of shear $(2-4 \mathrm{~m})$ was used on the shelf area to resolve small- scale internal waves and low resolution of shear $(8-16 \mathrm{~m})$ was often used in deep water to cover more water depth. Although the Richardson number calculated on $16 \mathrm{~m}$ shear might be overestimated, it does not affect the comparison of the Richardson number in different regions too much. One prominent feature in region 1 is that some turbulent patches with elevated dissipation rates $\left(\varepsilon>10^{-7} \mathrm{~W} \mathrm{~kg}^{-1}\right)$ and diapycnal diffusivities $\left(\kappa>10^{-4} \mathrm{~m}^{2} \mathrm{~s}^{-1}\right)$ were observed below the surface mixed layer. These turbulent patches often occurred at depths where the Richardson number was below 0.25 , for example, station 6 (between 175 and $195 \mathrm{~m}$ ), station 8 (between 80 and $100 \mathrm{~m}$ ), and station 11 (between 175 and $195 \mathrm{~m}$ ) (indicated by the arrows in Fig. 4), which suggests that elevated dissipation rates and diapycnal diffusivities in the turbulent patches are likely to result from shear instability. More detail regarding the shear instability will be discussed in the following text. Compared with region 1, turbulent mixing in regions 2-4 was relatively weak, with an average $\varepsilon$ and $\kappa$ in the upper $500 \mathrm{~m}$ (not including the surface mixed layer) of $1.1 \times 10^{-9} \mathrm{~W} \mathrm{~kg}^{-1}$ and $3.7 \times 10^{-6} \mathrm{~m}^{2} \mathrm{~s}^{-1}$, respectively. These two values are almost 1 order of magnitude smaller than those $\left(\varepsilon \sim 8.3 \times 10^{-9} \mathrm{~W} \mathrm{~kg}^{-1}\right.$ and $\kappa \sim 2.7 \times 10^{-5} \mathrm{~m}^{2} \mathrm{~s}^{-1}$ ) in region 1 . Weak turbulent mixing in regions $2-4$ is likely to be associated with the strong stratification and weak shear. $N^{2}$ (Fig. 4c) was greater than $S^{2}$ (Fig. 4d) in regions 2-4, with most of the water column occupied by a large Richardson number $(R i>10$; Fig. 4e).

To further understand the changing pattern of turbulence in the SCS, we now look in detail at the profiles of various quantities at three stations in different regions (Fig. 5): station 6 was from region 1, station 22 was from region 3 , and station 6 was from region 4. At station 6 in region 1 (Fig. 5a-e), the shear variance was slightly smaller than the buoyancy frequency squared over most of the water column (Fig. 5b). However, the shear variance exceeded the buoyancy frequency squared at some depths; for example, the shear variance was greater than the buoyancy frequency squared at a depth of $185 \mathrm{~m}$, pushing the Richardson number below 0.25 , which implies shear instability (Fig. 5c). Small overturns were also found in the density profile at depths of 175 to $195 \mathrm{~m}$ (Fig. 5a, the inset). The dissipation rates (Fig. 5d) and diapycnal diffusivities (Fig. 5e) at the corre- 

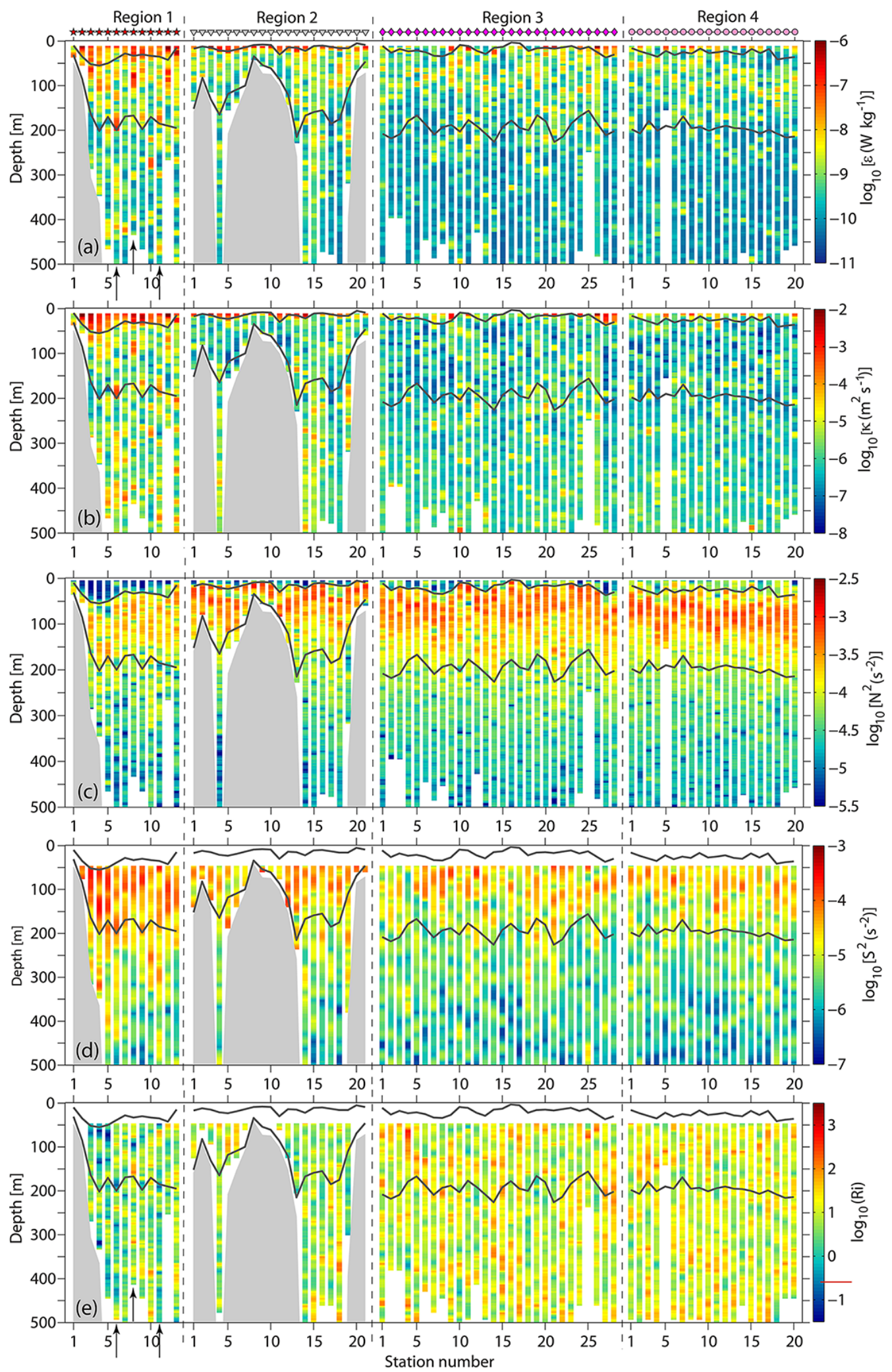

Figure 4. (a) Dissipation rate $(\varepsilon)$, (b) diapycnal diffusivity $(\kappa)$, (c) buoyancy frequency squared $\left(N^{2}\right)$, (d) shear variance $\left(S^{2}\right)$, and (e) Richardson number $(R i)$ from all of the stations. The gray shading indicates the bathymetry. In (a)-(e) the boundaries of the thermocline are indicated (gray curves). The red line on the color bar of (e) represents $R i=0.25$. The vertical dashed lines divide the stations into four regions with the symbols (red stars, gray triangles, magenta diamonds, and pink dots) shown at the top of (a). These symbols correspond to the station symbols in Fig. 1a. 

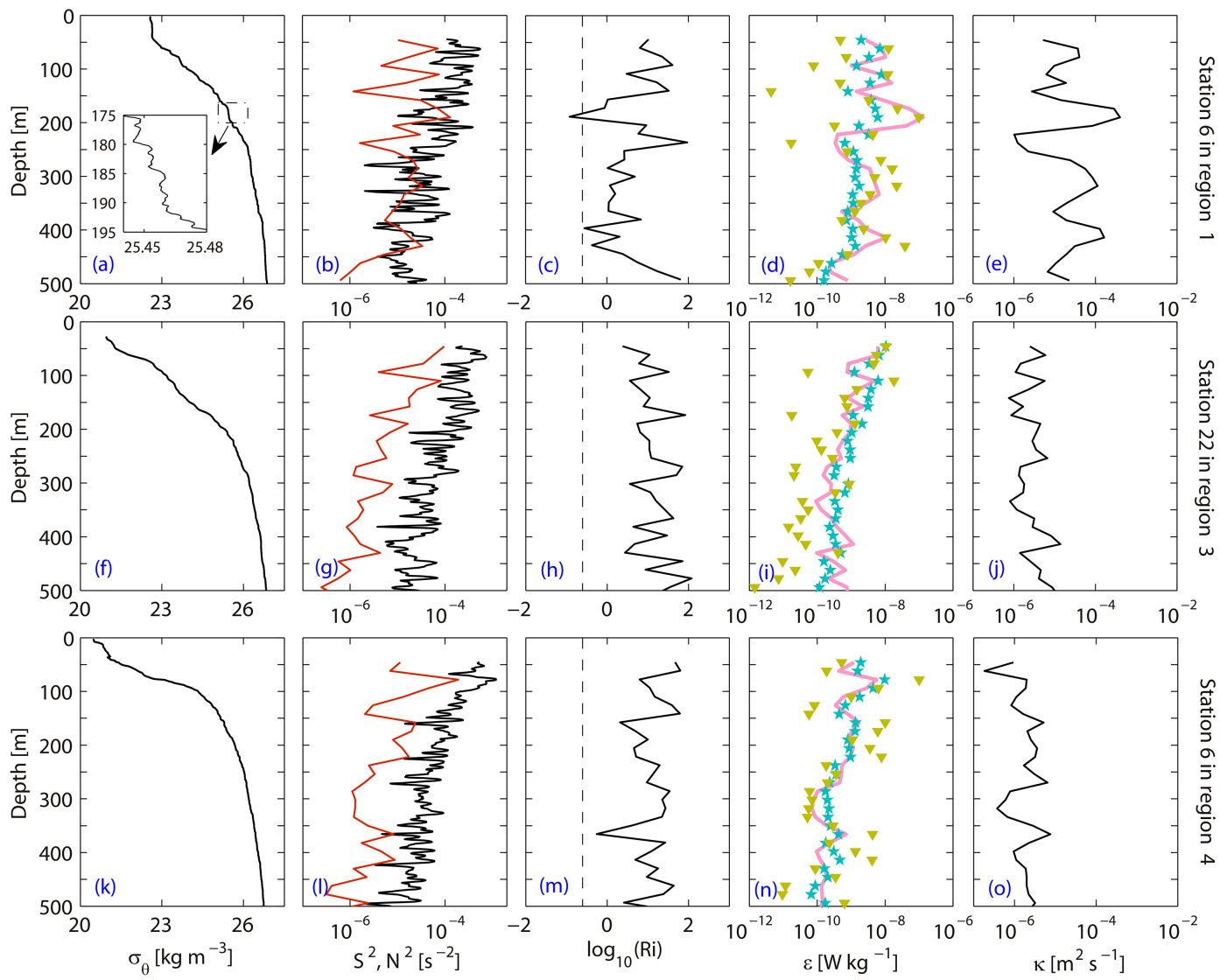

Figure 5. From top to bottom, three sets of profiles are from station 6 in region 1 (a, b, c, d, e), station 22 in region 3 (f, $\mathbf{g}, \mathbf{h}, \mathbf{i}, \mathbf{j})$, and station 6 in region $4(\mathbf{k}, \mathbf{l}, \mathbf{m}, \mathbf{n}, \mathbf{o})$. For each station, quantities plotted are (from left to right) potential density, shear variance (red) and buoyancy frequency squared (black), Richardson number (the vertical line indicates $R i=0.25$ ), observed (pink curves) and MG model (stars) and GH model (triangles) dissipation rates, and observed diapycnal diffusivity. The observed dissipation rate and diapycnal diffusivity have been vertically averaged over the $16 \mathrm{~m}$ ADCP bins. The inset in (a) enlarges the density profile to show the overturns.

sponding depths (175-195 m) were elevated by more than 1 order of magnitude, with the diapycnal diffusivities reaching $5.0 \times 10^{-4} \mathrm{~m}^{2} \mathrm{~s}^{-1}, 1$ to 2 orders of magnitude higher than the levels in an open ocean thermocline. The dissipation rates induced by shear instability contributed significantly to the turbulent mixing in the water column. Nearly $45 \%$ of the total dissipation rates in the upper $500 \mathrm{~m}$ (not including the surface mixed layer) was contributed by the elevated dissipation rates from the turbulent patch. The second and third sets of profiles were from region 3 (Fig. $5 \mathrm{f}-\mathrm{j}$ ) and region 4 (Fig. 5ko), respectively. The buoyancy frequency squared was higher than the shear variance (Fig. $5 \mathrm{~g}$ and 1), and no Richardson numbers below 0.25 were observed (Fig. $5 \mathrm{~h}$ and $\mathrm{m}$ ). The water column was occupied by dissipation rates ranging from $10^{-10}$ to $10^{-9} \mathrm{~W} \mathrm{~kg}^{-1}$ (Fig. 5i and $\mathrm{n}$ ) and diapycnal diffusivities of $10^{-6}$ to $10^{-5} \mathrm{~m}^{2} \mathrm{~s}^{-1}$ (Fig. $5 \mathrm{j}$ and o), comparable to the levels in an open ocean thermocline.

The above analysis indicates that high dissipation rates mainly occurred in the thermocline and the distribution of thermocline dissipation was spatially non-uniform. Turbulent mixing in the thermocline can be driven by various factors, such as surface wind, internal waves, and internal tides. In order to find out whether the turbulent mixing in the thermocline is driven by a single forcing or multiple forcing, we explore the probability density function (PDF) of dissipation rates estimated from a non-parametric PDF estimator (histogram). The PDFs of dissipation rates (Fig. 6) in the four regions do not show sharp shapes with a single significant peak. Instead, they show flat shapes with multiple peaks, especially the PDFs in regions 1 and 4 , which suggests that the turbulent mixing in the thermocline is driven by multiple forcing. To further explore the energy sources to the thermocline dissipation, we calculate the averaged dissipation rate $\langle\varepsilon\rangle_{\mathrm{T}}$ and the averaged diapycnal diffusivity $\langle\kappa\rangle_{\mathrm{T}}$ in the thermocline. $\langle\varepsilon\rangle_{\mathrm{T}}$ and $\langle\kappa\rangle_{\mathrm{T}}$ are given by

$\langle\varepsilon\rangle_{\mathrm{T}}=1 /\left(z_{\mathrm{b}}-z_{t}\right) \int_{z_{\mathrm{b}}}^{z_{\mathrm{t}}} \varepsilon \mathrm{d} z$ and $\langle\kappa\rangle_{\mathrm{T}}=1 /\left(z_{\mathrm{b}}-z_{t}\right) \int_{z_{\mathrm{b}}}^{z_{\mathrm{t}}} \kappa \mathrm{d} z$, 

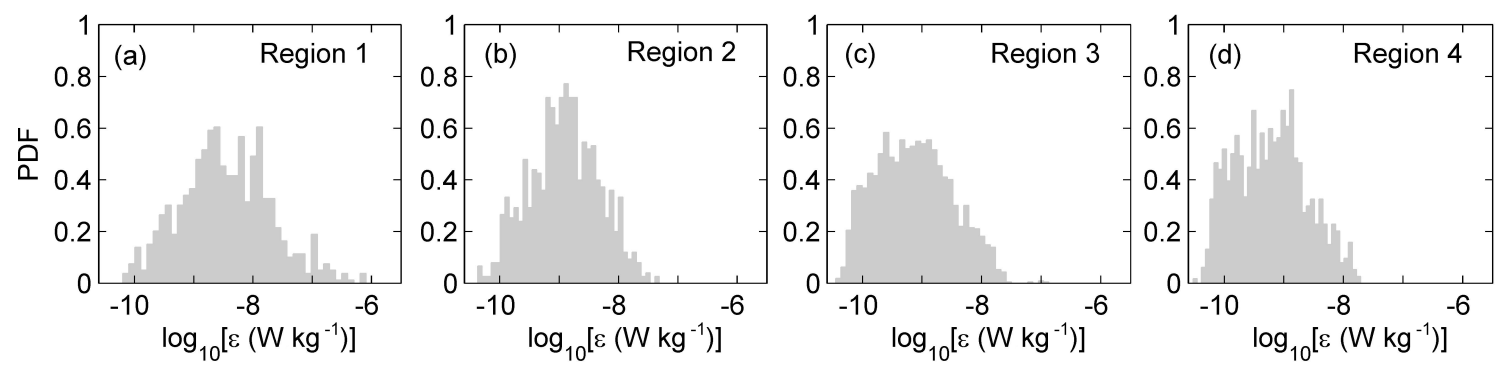

Figure 6. Probability density functions of dissipation rates in (a) region 1, (b) region 2, (c) region 3, and (d) region 4.

where $z_{\mathrm{b}}$ and $z_{\mathrm{t}}$ are the bottom and top of the thermocline, respectively. The dissipation rates and diapycnal diffusivities affected by the surface mixed layer were excluded before calculating $\langle\varepsilon\rangle_{\mathrm{T}}$ and $\langle\kappa\rangle_{\mathrm{T}}$. Figure $7 \mathrm{~b}$ shows the averaged dissipation rate in the thermocline. $\langle\varepsilon\rangle_{\mathrm{T}}$ decreased toward the south from $O\left(10^{-8} \mathrm{~W} \mathrm{~kg}^{-1}\right)$ in region 1 to $O\left(10^{-9} \mathrm{~W} \mathrm{~kg}^{-1}\right)$ in region 4 . In region 1 , $\langle\varepsilon\rangle_{\mathrm{T}}$ ranged from $1.8 \times 10^{-9}$ to $5.0 \times 10^{-8} \mathrm{~W} \mathrm{~kg}^{-1}$, with a mean value of $1.8 \times 10^{-8} \mathrm{~W} \mathrm{~kg}^{-1}$, which was 7 times, 9 times, and 12 times higher than the mean values of region $2\left(2.5 \times 10^{-9} \mathrm{~W} \mathrm{~kg}^{-1}\right)$, region $3\left(2.1 \times 10^{-9} \mathrm{~W} \mathrm{~kg}^{-1}\right)$, and region $4\left(1.5 \times 10^{-9} \mathrm{~W} \mathrm{~kg}^{-1}\right)$, respectively. Elevated $\langle\kappa\rangle_{\mathrm{T}}$ was also observed in region 1 (Fig. 7c). The average $\langle\kappa\rangle_{\mathrm{T}}$ in region 1 was $3.5 \times 10^{-5} \mathrm{~m}^{2} \mathrm{~s}^{-1}$, which was an order of magnitude greater than the values of region 2 $\left(3.3 \times 10^{-6} \mathrm{~m}^{2} \mathrm{~s}^{-1}\right)$, region $3\left(2.2 \times 10^{-6} \mathrm{~m}^{2} \mathrm{~s}^{-1}\right)$, and region $4\left(2.1 \times 10^{-6} \mathrm{~m}^{2} \mathrm{~s}^{-1}\right)$. One prominent feature in the northern SCS is that the mean of $\langle\kappa\rangle_{\mathrm{T}}$ in region 1 was 11 times higher than the value in region 2 , while the mean of $\langle\varepsilon\rangle_{\mathrm{T}}$ in region 1 was only 7 times higher than that the value in region 2. This difference mainly resulted from the weak stratification in region 1 (Fig. 4c).

Microstructure measurements at different stations were taken at different times and the measurement time might be one of the factors that affect the variability of $\langle\varepsilon\rangle_{\mathrm{T}}$ and $\langle\kappa\rangle_{\mathrm{T}}$. Strong turbulent mixing generally occurs during spring tides (Peters and Bokhorst, 2000). Thus it is possible that microstructure measurements in region 1 were taken during spring tides and those in regions $2-4$ were taken during neap tides, and the elevated turbulent mixing in region 1 may result from a different measurement time. To rule out this possibility, we obtained the barotropic tides from the global inverse tide model (TPXO; Egbert and Erofeeva, 2002), which give us the time information of spring-neap tides during the period of observation. Only the barotropic tides at $18^{\circ} \mathrm{N}, 114^{\circ} \mathrm{E}$ were extracted because the bias in the arrival of spring-neap tides in different locations of the SCS is small (no longer than $3 \mathrm{~h}$, not shown). The 14-day springneap cycles were well represented in the extracted barotropic tides (Fig. 7d). A comparison of $\langle\varepsilon\rangle_{\mathrm{T}}$ and $\langle\kappa\rangle_{\mathrm{T}}$ to the extracted tides suggests that elevated turbulent mixing in region 1 was not attributed to the measurement time; for example, stations in regions 1 and 3 spanned neap and spring tides (see Fig. 7d, stars and diamonds), but the averaged $\langle\varepsilon\rangle_{\mathrm{T}}$ and $\langle\kappa\rangle_{\mathrm{T}}$ in region 1 were still an order of magnitude greater than the values in region 3 (Fig. $7 b$ and c).

Surface wind is an important energy source for the turbulence in the ocean (Brainerd and Gregg, 1993; Burchard and Rippeth, 2009; Matsuno et al., 2005; Shay and Gregg, 1986), and indirectly enhances the turbulence in the thermocline through inertial-gravity wave motion generated by surface wind stress. To find out whether surface wind affects the turbulence in the thermocline significantly, we estimate the wind energy flux. The wind energy flux (Yang et al., 2014) at a height of $10 \mathrm{~m}, E_{10}$, is given by $E_{10}=\rho_{\mathrm{a}} C_{\mathrm{D}} U_{10}^{3}$, where $\rho_{\mathrm{a}}=1.2 \mathrm{~kg} \mathrm{~m}^{-3}$ is the air density, $C_{\mathrm{D}}$ is the drag coefficient with a value of $1.14 \times 10^{-3}$ (Large and Pond, 1981), and $U_{10}$ is the wind speed at $10 \mathrm{~m}$. The wind speed data during the observation come from the European Centre for Medium-Range Weather Forecasts (http://apps.ecmwf.int/datasets/data/interim-full-daily/ levtype=sfc/). The variability of $E_{10}$ is shown in Fig. 7a. Winds were light $\left(U_{10}<9 \mathrm{~m} \mathrm{~s}^{-1}\right)$ at all the stations with $E_{10}<1.0 \mathrm{~W} \mathrm{~m}^{-2}$ except for stations $11-13$ in region 1 . The influence of wind stress on the variability of turbulence in the thermocline was small, as one can see from Fig. $7 \mathrm{a}-\mathrm{c}$ that the variability of $\langle\varepsilon\rangle_{\mathrm{T}}$ and $\langle\kappa\rangle_{\mathrm{T}}$ did not follow the variability of $E_{10}$. The values of $E_{10}\left(10^{-1} \mathrm{~W} \mathrm{~m}^{-2}\right)$ at stations $1-9$ in region 4 were an order of magnitude larger than that at stations 1-7 in region 1, while the values of $\langle\varepsilon\rangle_{\mathrm{T}}$ and $\langle\kappa\rangle_{\mathrm{T}}$ at stations 1-9 in region 4 were almost an order of magnitude smaller than that at stations 1-7 in region 1 . Evidence can also be found from the comparison between $\langle\kappa\rangle_{\mathrm{T}}$ and averaged wind speed during the cruises (Fig. 1b). The average winds were evenly distributed over the SCS, which is significantly different from the spatial distribution of $\langle\kappa\rangle_{\mathrm{T}}$. These observations suggest that the contribution of surface winds to the observed strong turbulence in region 1 was small. Measurements from Matsuno and Wolk (2005) also indicate that the contribution of surface winds to the turbulence below the surface mixing layer was small during light winds and that only when the wind speed reached $10 \mathrm{~m} \mathrm{~s}^{-1}$ would wind stirring have made a notable contribution to the turbulence below the surface mixing layer. 

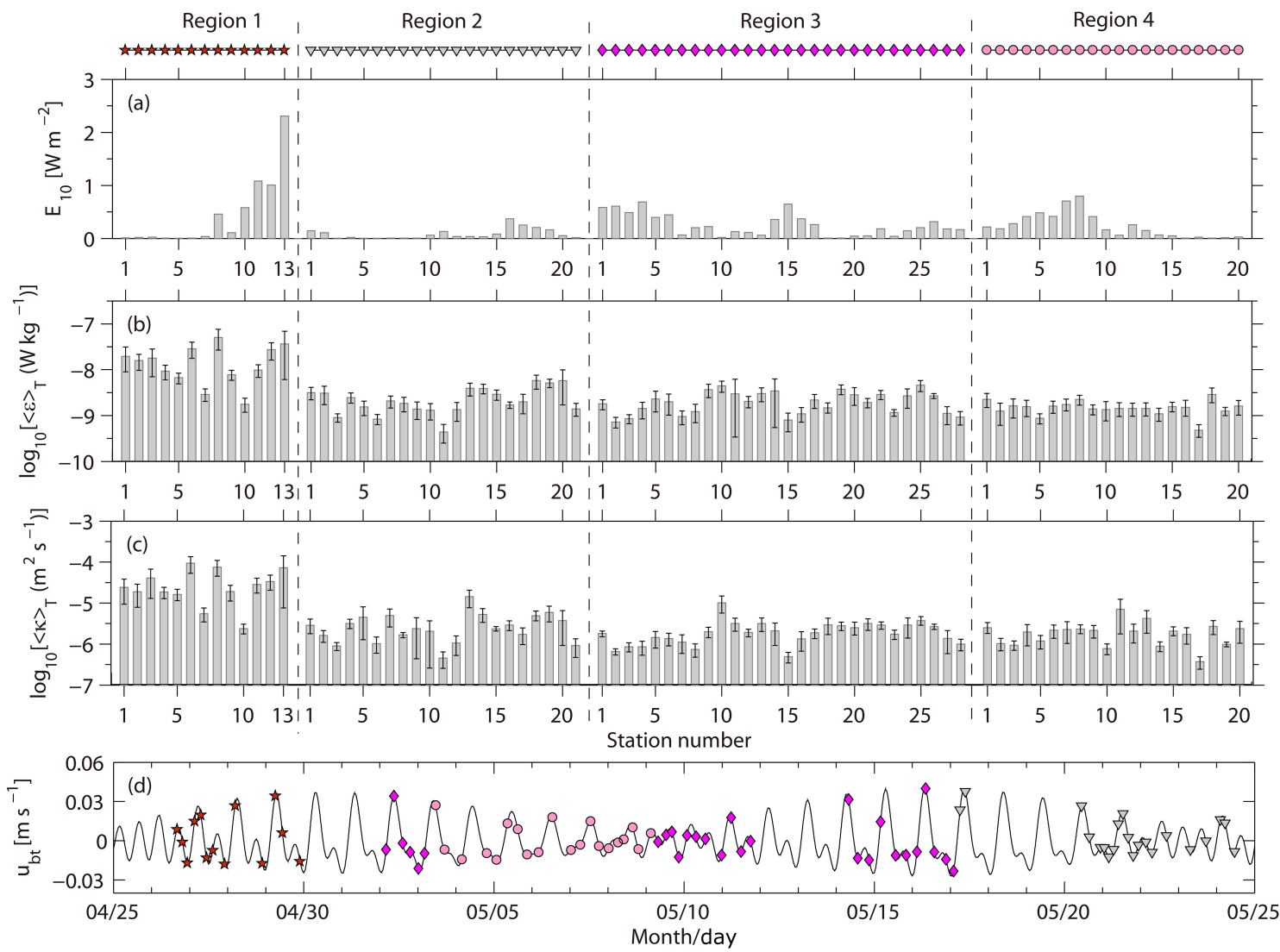

Figure 7. (a) Wind energy flux $E_{10}$ for each station during the TurboMAP measurement. (b) The average dissipation rate $\langle\varepsilon\rangle_{\mathrm{T}}$ and (c) average diapycnal diffusivity $\langle\kappa\rangle_{\mathrm{T}}$ in the thermocline. The vertical bars in (b) and (c) indicate the $95 \%$ bootstrapped confidence interval. The vertical dashed lines divide the stations into four regions with symbols (red stars, gray triangles, magenta diamonds, and pink dots) shown at the top of (a). These symbols correspond to the station symbols in Fig. 1a. (d) Time series of the barotropic tidal velocity $\left(u_{\mathrm{bt}}\right)$ predicted from TPXO 7.1 with the station symbols overlain.

Internal waves and internal tides are candidates that contribute to the elevated turbulent mixing in region 1 . It is known that internal waves can provide large amounts of energy for turbulence in the ocean (Alford et al., 2015). Internal waves are unevenly distributed throughout the SCS. Most of the internal waves and internal tides originate in the Luzon Strait and propagate northwestwards through the deep water zone near the Luzon Strait to the continental shelf (Guo and Chen, 2014; Klymak et al., 2006b; Lien et al., 2005; Ramp et al., 2004; Zhao, 2014; Zhao et al., 2004). Internal wave packets derived from satellite images by Zhao et al. (2004) are shown in Fig. 1b for reference. Most of the internal wave packets occurred on the continental shelf in region 1 where $\langle\kappa\rangle_{\mathrm{T}}$ can be $10^{-5}-10^{-4} \mathrm{~m}^{2} \mathrm{~s}^{-1}$, almost an order of magnitude greater than that on the adjacent continental shelf in region 2. A report based on mooring data (Lien et al., 2014) indicates that internal waves would induce strong shear during propagation. Strong shear was also found in region 1 in our measurement (Fig. 4d). These observations suggested that internal waves and internal tides generated near the Luzon
Strait are expected to make a dominant contribution to the elevated turbulence in region 1 .

\subsection{Parameterizations of turbulence}

In this section we evaluate two models for parameterizing the dissipation rate in terms of more easily observed or modeled quantities, such as stratification and shear. One wave-wave interaction parameterization (Gregg, 1989; MacKinnon and Gregg, 2003a) in the open ocean is the Gregg-Henyey scaling (known as the $\mathrm{GH}$ model) given by

$$
\begin{aligned}
\varepsilon_{\mathrm{GH}} & =\alpha_{0}\left[f \cosh ^{-1}\left(\frac{N_{0}}{f}\right)\right]\left(\frac{S^{4}}{S_{\mathrm{GM}}^{4}}\right)\left(\frac{N^{2}}{N_{0}^{2}}\right) \text { and } \\
S_{\mathrm{GM}}^{4} & =\beta_{0}\left(\frac{N^{2}}{N_{0}^{2}}\right)^{2},
\end{aligned}
$$

where $\alpha_{0}=1.8 \times 10^{-6} \mathrm{~J} \mathrm{~kg}^{-1}, f$ is the Coriolis frequency, $S$ is the low-frequency/low-mode resolved shear, $N_{0}$ is a reference buoyancy frequency, $\cosh ^{-1}$ denotes the inverse 
hyperbolic cosine function, and $\beta_{0}=1.66 \times 10^{-10} \mathrm{~s}^{-4}$. Another analytical model (MacKinnon and Gregg, 2003a) is the MacKinnon-Gregg model (known as the MG model) given by

$\varepsilon_{\mathrm{MG}}=\varepsilon_{0}\left(\frac{N}{N_{0}}\right)\left(\frac{S}{S_{0}}\right)$,

where $S_{0}=N_{0}=5.1 \times 10^{-3} \mathrm{rad} \mathrm{s}^{-1}$ and $\varepsilon_{0}$ is an adjustable constant that gives the model dissipation rate the same cruise average as the observational data. The adjustable constant $\varepsilon_{0}$ shows great variability in different regions and seasons, spanning from $10^{-10}$ to more than $10^{-8} \mathrm{~W} \mathrm{~kg}^{-1}$ (MacKinnon and Gregg, 2005; Palmer et al., 2008; van der Lee and Umlauf, 2011; Xie et al., 2013). This regional and temporal variability of $\varepsilon_{0}$ strongly suggests the importance of different physical processes for setup and maintenance of the background levels of turbulent dissipation. Here, we assess the two models for parameterization of the turbulence in the northern SCS (dissipation data are from the stations in region 1 and region 2), central SCS (dissipation data are from the stations in region 3), and southern SCS (dissipation data are from the stations in region 4). Different values of parameter $\varepsilon_{0}$ are selected for the parameterizations due to their different mixing backgrounds: $\varepsilon_{0}=1.65 \times 10^{-9} \mathrm{~W} \mathrm{~kg}^{-1}$ for the northern SCS, $\varepsilon_{0}=0.96 \times 10^{-9} \mathrm{~W} \mathrm{~kg}^{-1}$ for the central SCS, and $\varepsilon_{0}=0.50 \times 10^{-9} \mathrm{~W} \mathrm{~kg}^{-1}$ for the southern SCS. All of the data affected by the surface mixed layers or bottom mixed layers were excluded for the parameterizations. To reduce the bias introduced by the different vertical resolutions of the shear and stratification data, $16 \mathrm{~m}$ buoyancy frequency and $16 \mathrm{~m}$ shear were used in the parameterization; i.e., density was first interpolated onto the ADCP grid and $N^{2}$ was computed from finite differencing. Accordingly, the dissipation rates were vertically averaged over the $16 \mathrm{~m}$ ADCP bins.

Figure 8 shows the distribution of dissipation rates (observed and modeled) in $N^{2}$ and $S^{2}$ space. The observed dissipation rates in the SCS (Fig. 8, left column) increase with increasing buoyancy frequency and shear. The GH model fails to reproduce these kinematic relationships (Fig. 8, right column). The dependence of $\varepsilon_{\mathrm{GH}}$ on shear is too strong, with the dissipation rates underestimated in weak shear. $\varepsilon_{\mathrm{GH}}$ also varies inversely with the buoyancy frequency for a given level of shear, contrary to the observation (Fig. 8, left column). Instead, the MG model dissipation rates (Fig. 8, middle column) display a pattern qualitatively consistent with the observed data (Fig. 8, left column). Both the observed and MG model dissipation rates scale positively with shear and the buoyancy frequency. In the northern SCS, the turbulence was more complicated than the predictions of the MG model. The MG model (Fig. 8b) underestimates the elevated dissipation rates that scattered in Fig. 8a; for example, the MG model underestimates the elevated dissipation rates at $\left(N^{2}=6.5 \times 10^{-5}, S^{2}=5.0 \times 10^{-6} \mathrm{~s}^{-2}\right),\left(N^{2}=\right.$ $\left.1.0 \times 10^{-4}, S^{2}=1.0 \times 10^{-5} \mathrm{~s}^{-2}\right)$, and $\left(N^{2}=7.9 \times 10^{-5}\right.$, $S^{2}=2.0 \times 10^{-5} \mathrm{~s}^{-2}$ ).
Figure 9 shows the dissipation rate binned in terms of stratification or shear alone. They are equivalent to integrating the two-dimensional plots in Fig. 8 horizontally and vertically. Both models reproduce the slope of the dissipation rate versus the buoyancy frequency ( $\varepsilon \propto N^{2}$; Fig. 9a, c, and e), though the GH model dissipation rates are too large on average. However, the two models show large differences in the trend of the dissipation rate versus shear (Fig. 9b, d, and f). The MG model successfully captures the essential kinematic relationship between the dissipation rate and shear, whereas the GH model dissipation rates have a much steeper relationship with shear. Comparing the three regions, we find that the confidence intervals of the observed dissipation rates in the northern SCS (Fig. 9a and b) were wider than those in the central and southern SCS (Fig. 9c-f). In addition, the observed dissipation rates in the northern SCS were slightly larger and showed greater fluctuations than the MG model dissipation rates (Fig. 9a and b). The wide confidence intervals and high observed dissipation rates in Fig. 9a and b mainly resulted from the elevated dissipation rates scattered in Fig. 8a. The MG model underestimated these elevated dissipation rates (comparing Fig. 8a with Fig. 8b). To explore these underestimations, we directly compared the model dissipation rates with the observed dissipation rates at three selected stations (Fig. 5, fourth column). For the stations from regions 3 and 4 (Fig. 5i and n), the relationships between the observed dissipation rates (pink curves) and the GH model dissipation rates (triangles) were poor, with the GH model dissipation rates deviating from the observed data by 1 order of magnitude. Instead, the MG model dissipation rates (stars) fared better than the GH model dissipation rates against the observed data. For station 6 from region 1 (Fig. 5d), the GH model dissipation rates also failed to overlap the observed data. Instead, the MG model dissipation rates agreed quite well with the observed data, except for the elevated dissipation rates induced by shear instability; for example, the MG model underestimated the elevated dissipation rates at depths of 175 to $195 \mathrm{~m}$ by more than 1 order of magnitude. The elevated dissipation rates scattered in Fig. 8a mainly resulted from the dissipation rates induced by shear instability. However, the GH model dissipation rates seemed to agree with the elevated dissipation rates induced by shear instability $(175-195 \mathrm{~m})$. This agreement might be due to the fact that dissipation rates resulting from shear instability depend on the Richardson number, and the GH model also demonstrates Richardson number dependency.

To assess the efficacy of the models in estimating the dissipation rates, we show a direct comparison of observed dissipation rates versus modeled dissipation rates in Fig. 10. It can be seen from Fig. 10 that the MG model predicts the magnitude of the dissipation rates better than the GH model. The linear fittings of the data, $\log _{10}\left(\varepsilon_{\mathrm{OB}}\right)=\alpha \log _{10}\left(\varepsilon_{\mathrm{M}}\right)+\beta$, are also shown in Fig. 10, where $\varepsilon_{\mathrm{M}}$ represent the modeled dissipation rates. Parameters $\alpha$ and $\beta$ are given in Table 2 . We also test the linear regression with a $t$-test (Rice, 2006), 

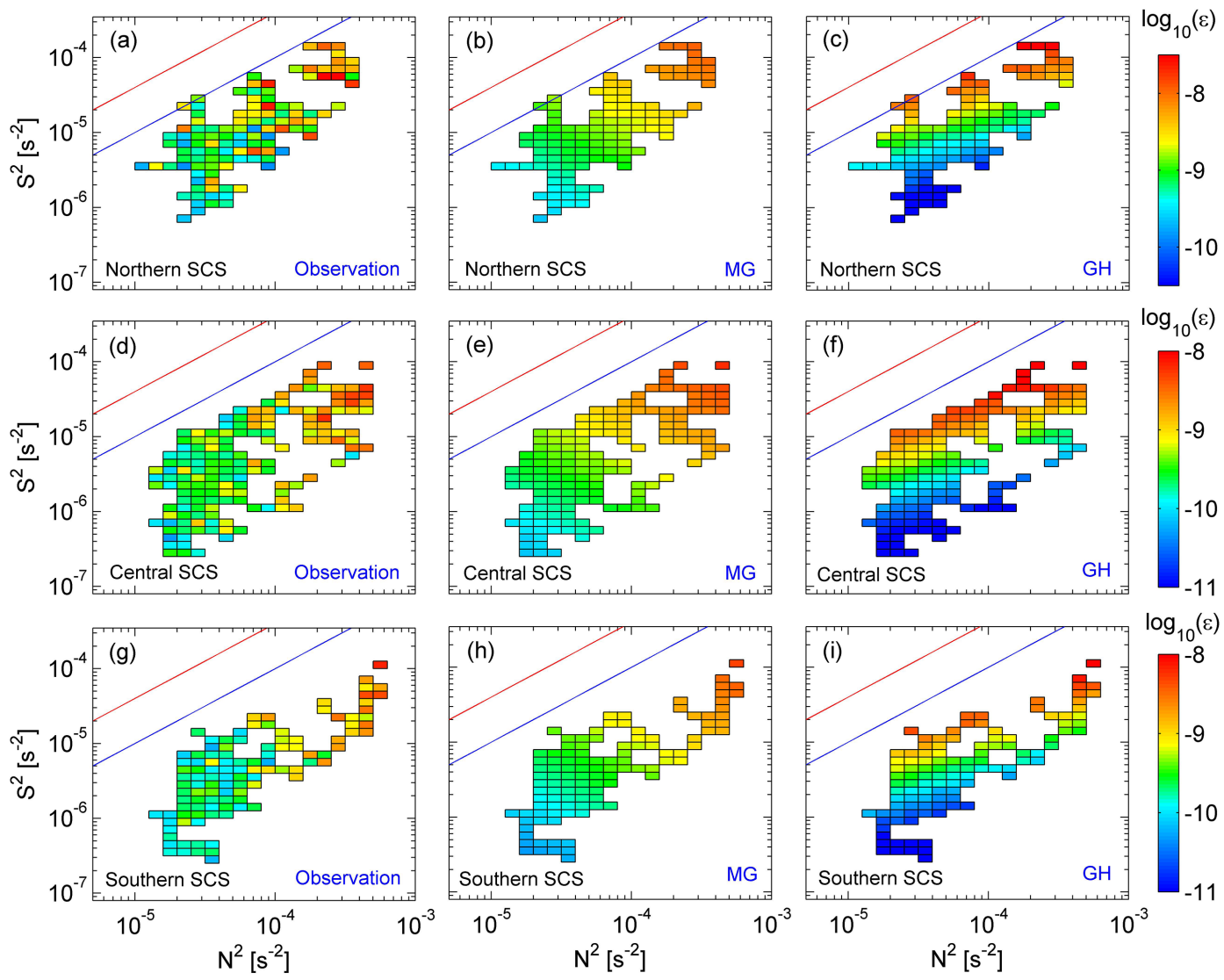

Figure 8. Dissipation rates of observation $\varepsilon_{\mathrm{OB}}$ (left column), MG model $\varepsilon_{\mathrm{MG}}$ (middle column), and GH model $\varepsilon_{\mathrm{GH}}$ (right column) averaged in bins of $16 \mathrm{~m}$ buoyancy frequency squared $\left(N^{2}\right)$ and $16 \mathrm{~m}$ shear variance $\left(S^{2}\right)$. All data affected by the surface mixed layers or bottom mixed layers were excluded. (a)-(c) show the results of the stations in the northern SCS, (d)-(f) show the results of the stations in the central SCS, and (g)-(i) show the results of the stations in the southern SCS. The boundaries of $R i=0.25$ (oblique red lines) and $R i=1$ (oblique blue lines) are shown for reference.

and the results are given in Table 2. For the MG model, the two-tailed test $p$-values for the northern, central, and southern SCS are 0.9966, 0.988, and 0.9651, respectively. These values are larger than 0.05 , which suggests no significant difference between the observed and fitted values. However, for the GH model, the two-tailed test $p$-values for the northern (0.0087), central (0.0053), and southern (0.0476) SCS are smaller than 0.05 , which suggests that there are significant differences between the observed and fitted values. The coefficients of determination $\left(R^{2}\right)$ are also given in Table 2. $R^{2}$ is the ratio of the difference between the variance of the observed values and the variance of the residuals from the fit to the variance of the observed values (Rice, 2006). It can be interpreted as the proportion of the variability of the observed values that can be explained by the fitted values. The values of $R^{2}$ from the MG model are larger than those from the GH model, which suggests that the MG model predicts the observed data better than the GH model. For the MG model, large $R^{2}$ in the central and southern SCS suggest that the MG model works better in the central and southern SCS than in the northern SCS. Small $R^{2}$ in the northern SCS is mainly due to the elevated dissipation rates induced by shear instability since the MG model largely underestimates these dissipation rates.

\section{Discussion}

Our observations indicate that turbulent mixing in the upper ocean of the SCS is spatially non-uniform, with strong turbulent mixing found in the northern SCS. This spatial pattern is consistent with the mixing distribution reported by Yang et al. (2016). Our estimates of diapycnal diffusivity $\left(\sim 10^{-5} \mathrm{~m}^{2} \mathrm{~s}^{-1}\right)$ in region 1 are similar to those $\left(\sim 10^{-5} \mathrm{~m}^{2} \mathrm{~s}^{-1}\right)$ of Tian et al. (2009) but almost 2 orders of magnitude smaller than those $\left(\sim 10^{-3} \mathrm{~m}^{2} \mathrm{~s}^{-1}\right)$ reported by Yang et al. (2016); these different values might be attributed to various factors such as estimation methods and observation seasons. Diapycnal diffusivities from Tian et al. (2009) and Yang et al. (2016) were estimated with Gregg-HenyeyPolzin parameterizations, which depends on reference dissipation. Different reference dissipations chosen in the param- 

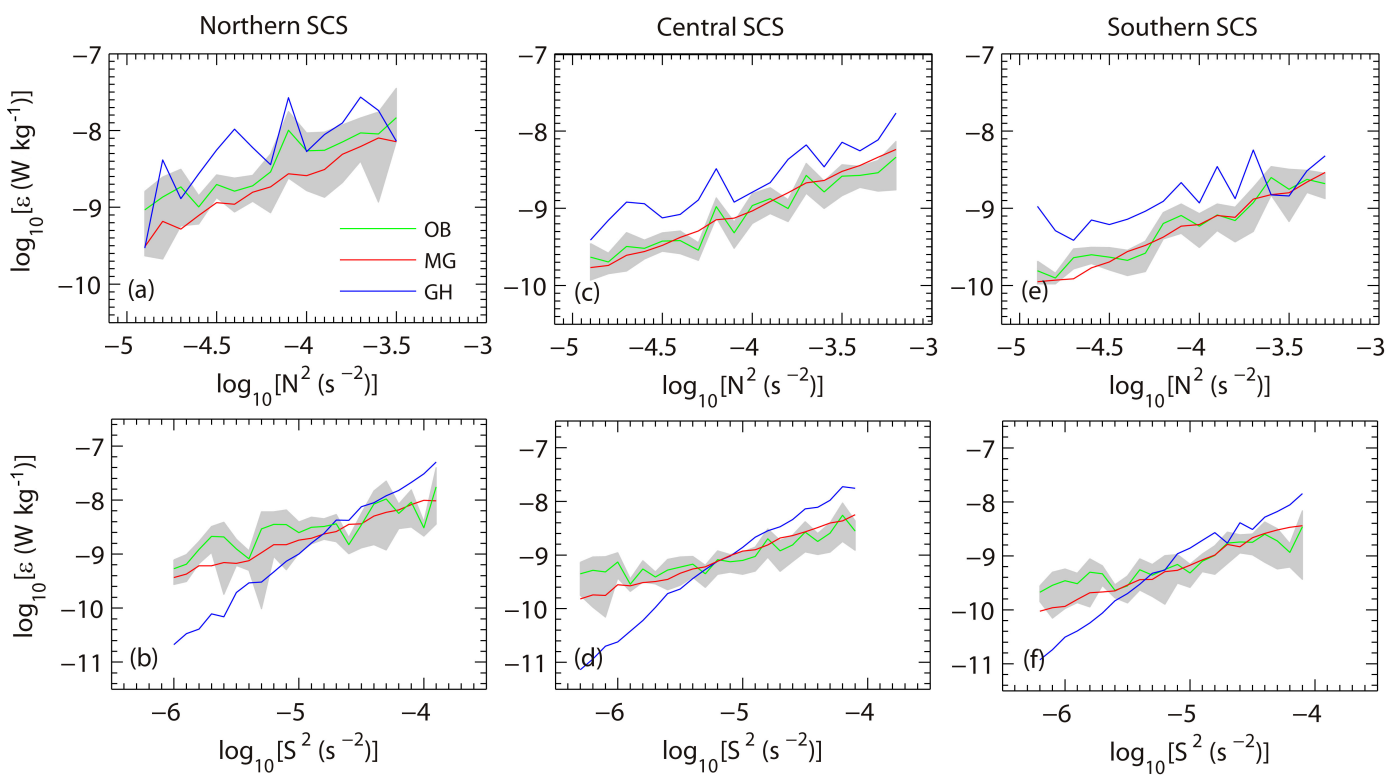

Figure 9. Average dissipation rate calculated in bins of buoyancy frequency squared $\left(N^{2}\right)$ and shear variance $\left(S^{2}\right)$ for the northern $S C S($ ab), central SCS (c-d), and southern SCS (e-f). The green, red, and blue curves are the results of the observation, MG model, and GH model, respectively. The grey shading indicates the $95 \%$ bootstrapped confidence interval for the observed dissipation rates.
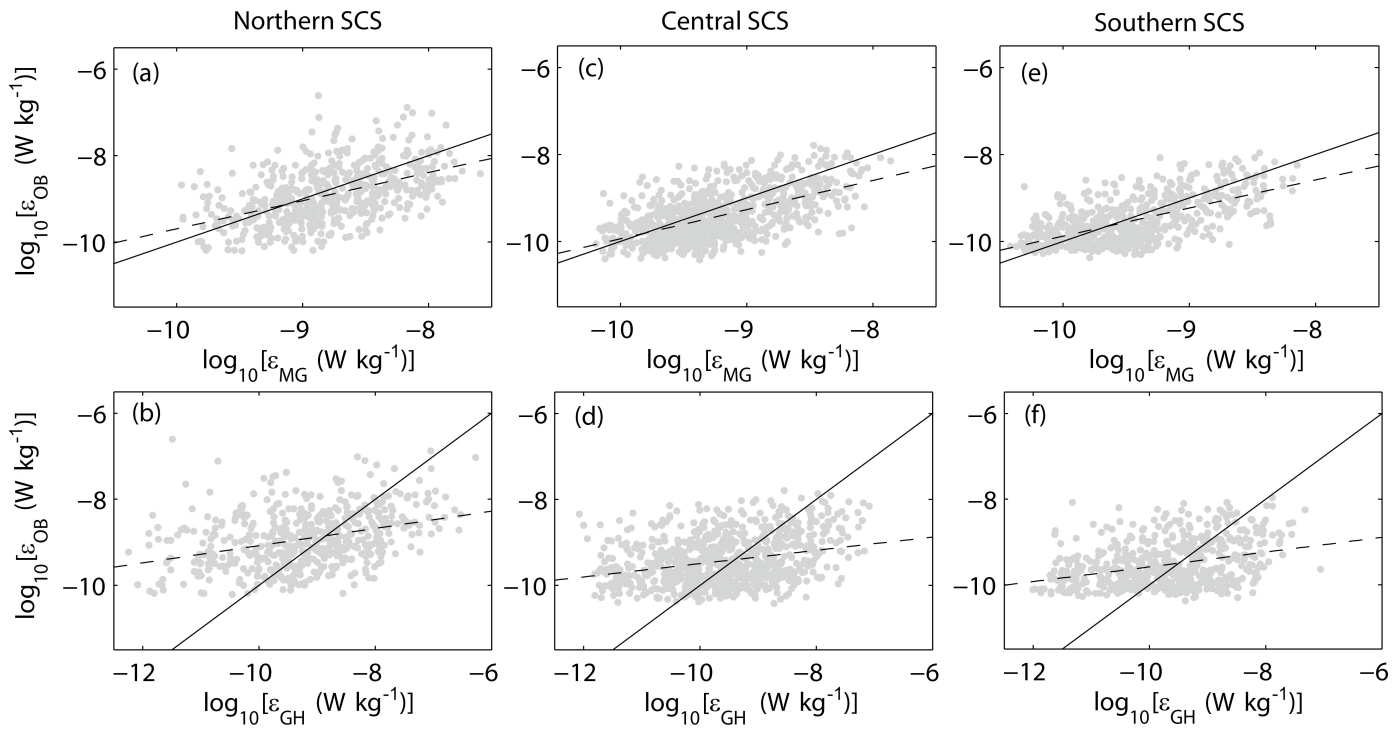

Figure 10. Observed dissipation ( $\left.\varepsilon_{\mathrm{OB}}\right)$ plotted against modeled (top) MG and (bottom) GH dissipation for the northern SCS (a-b), central SCS (c-d), and southern SCS (e-f). The solid lines indicate the one-to-one relation: $\log _{10}\left(\varepsilon_{\mathrm{OB}}\right)=\log _{10}\left(\varepsilon_{\mathrm{GH}}\right)$ or $\log _{10}\left(\varepsilon_{\mathrm{OB}}\right)=\log _{10}\left(\varepsilon_{\mathrm{MG}}\right)$. The dash lines indicate the linear fittings of the data.

eterization can make the estimated diapycnal diffusivity different. In addition, the data used in the parameterization of Yang et al. (2016) span from 2005 to 2012 and cover all the year round, while the microstructure data in our observation just cover 1 month. Seasonal and inter-annual variations of internal waves in the SCS (Huang et al., 2008; Yang et al., 2009) might affect the turbulent mixing.
The GH model and the MG model were derived from the eikonal model of Henyey et al. (1986) which is applicable to parameterize the dissipation controlled by wave-wave interactions that transfer energy from large-scale waves to smallscale waves (MacKinnon and Gregg, 2005). The GH model is based on the assumption that the waves are statistically stationary, with the energy of small-scale waves and the shear of the large-scale waves maintaining a particular relation- 
Table 2. Results of the linear regression and $t$-test.

\begin{tabular}{llrrrrr}
\hline Location & Model & $\alpha$ & $\beta$ & $t$ value & $\begin{array}{r}\text { Sig. } \\
\text { (two-tailed) }\end{array}$ & $R^{2}$ \\
\hline \multirow{2}{*}{ Northern SCS } & MG & 0.6517 & -3.178 & 0.0042 & 0.9966 & 0.2373 \\
& GH & 0.2 & -7.0805 & -2.628 & 0.0087 & 0.1098 \\
\hline Central SCS & MG & 0.6721 & -3.2202 & -0.0151 & 0.988 & 0.3352 \\
& GH & 0.1546 & -7.9507 & -2.7892 & 0.0053 & 0.1267 \\
\hline \multirow{2}{*}{ Southern SCS } & MG & 0.646 & -3.421 & -0.0437 & 0.9651 & 0.3799 \\
& GH & 0.1724 & -7.8608 & -1.9827 & 0.0476 & 0.1687 \\
\hline
\end{tabular}

ship through the Garrett-Munk (GM) spectrum (Garrett and Munk, 1975). It is typically evaluated for the internal wave field with the GM spectral shape (Gregg, 1989). The MG model was first proposed by MacKinnon and Gregg (2003) to parameterize the turbulence over the continental shelf. It is found to be suitable for the wave field of the continental shelf in which the energy and shear are dominated by the near-inertial motions, internal tides, or low-frequency internal waves (MacKinnon and Gregg, 2003a; Palmer et al., 2008; van der Lee and Umlauf, 2011). Recently it was found that the MG model also successfully parameterizes the turbulent mixing in the upper layer of the deep sea (Xie et al., 2013).

Statistical analysis shows the dissipation rates in the SCS to be proportional to both the shear and buoyancy frequencies, in marked contrast to the predictions of the GH model, but consistent with the predictions of the MG model. The disagreement of the GH model might be associated with the wave field in the SCS. Previous studies (Polzin et al., 1995; Wijesekera et al., 1993) have indicated that the predictions of the GH model would exhibit departure from the observed dissipation by more than 1 order of magnitude in regions where the wave field deviates from the GM spectrum. Thus, it is appropriate to examine the wave field in the SCS. Data obtained from six moorings deployed in the SCS (Fig. 1a, yellow squares) were used to estimate the horizontal kinetic energy spectra. Though the data were obtained from different periods, they reflected the main characteristics of the wave field in the SCS. The spectra (Fig. 11) show significant peaks in the local inertial $(f)$ and tidal frequencies (diurnal $O_{1}$ and $K_{1}$; semidiurnal $M_{2}$ ); these peaks imply that energy was primarily dominated by the near-inertial motions and internal tides. Within the internal wave band, significant peaks were also observed at higher tidal harmonic frequencies such as $D_{3}, D_{4}$, and $D_{5}$ (respectively, about three, four, and five cycles per day). These higher tidal harmonic frequencies mainly result from nonlinear interaction between internal waves (van Haren, 2003; van Haren et al., 2002; Xie et al., 2010). These energetic internal tides and harmonic internal waves cannot be well described by the GM spectrum. Furthermore, the spectra deviated from the GM spectrum at high frequencies ( $\sigma>3 \mathrm{cpd})$, which is especially evident in the spectra of the moorings from the northern SCS (mooring 1) and southern SCS (mooring 3). These observations are not supportive of the assumption that the GH model is based on. In contrast, some of our observations support the MG model, such as the wave field being dominated by nearinertial waves and internal tides, and the dissipation rates scale positively with shear and stratification. Overall, the MG model succeeds in parameterizing the turbulence in the SCS, except for some elevated dissipation rates induced by shear instability. The MG model tends to underestimate these elevated dissipation rates. This is not surprising because the MG model, which is based on wave-wave interactions, represents bulk averages of turbulent properties and does not reproduce individual shear instability events (MacKinnon and Gregg, 2005).

\section{Summary}

We analyzed observations of turbulent dissipation and mixing in the SCS with microstructure data obtained from 26 April to 23 May 2010. The observations are divided into four regions: region 1 is located to the west of the Luzon Strait, region 2 is located to the northeast of Hainan Island, region 3 is located in the central SCS, and region 4 is located in the southern SCS. Strong turbulent mixing was observed in region 1 , with the mean $\langle\varepsilon\rangle_{\mathrm{T}}$ reaching $1.8 \times 10^{-8} \mathrm{~W} \mathrm{~kg}^{-1}$, which is 9 times and 12 times larger than the values in the central $\left(2.1 \times 10^{-9} \mathrm{~W} \mathrm{~kg}^{-1}\right)$ and southern $\left(1.5 \times 10^{-9} \mathrm{~W} \mathrm{~kg}^{-1}\right) \mathrm{SCS}$, respectively. Elevated $\langle\kappa\rangle_{\mathrm{T}}$ were also found in region 1, i.e., $O\left(10^{-5} \mathrm{~m}^{2} \mathrm{~s}^{-1}\right)$, which is almost an order of magnitude higher than the values of the central and southern SCS. The turbulent mixing in different regions displays different mixing features, to which shear variance and stratification have made a significant contribution. In region 1, the shear was stronger and the stratification was weaker than those in other regions. Shear instability events occasionally occurred in these conditions and produced elevated dissipation and diapycnal diffusivity. Although the turbulent patches induced by shear instability were occasional and sparse, they significantly contributed to the tur- 

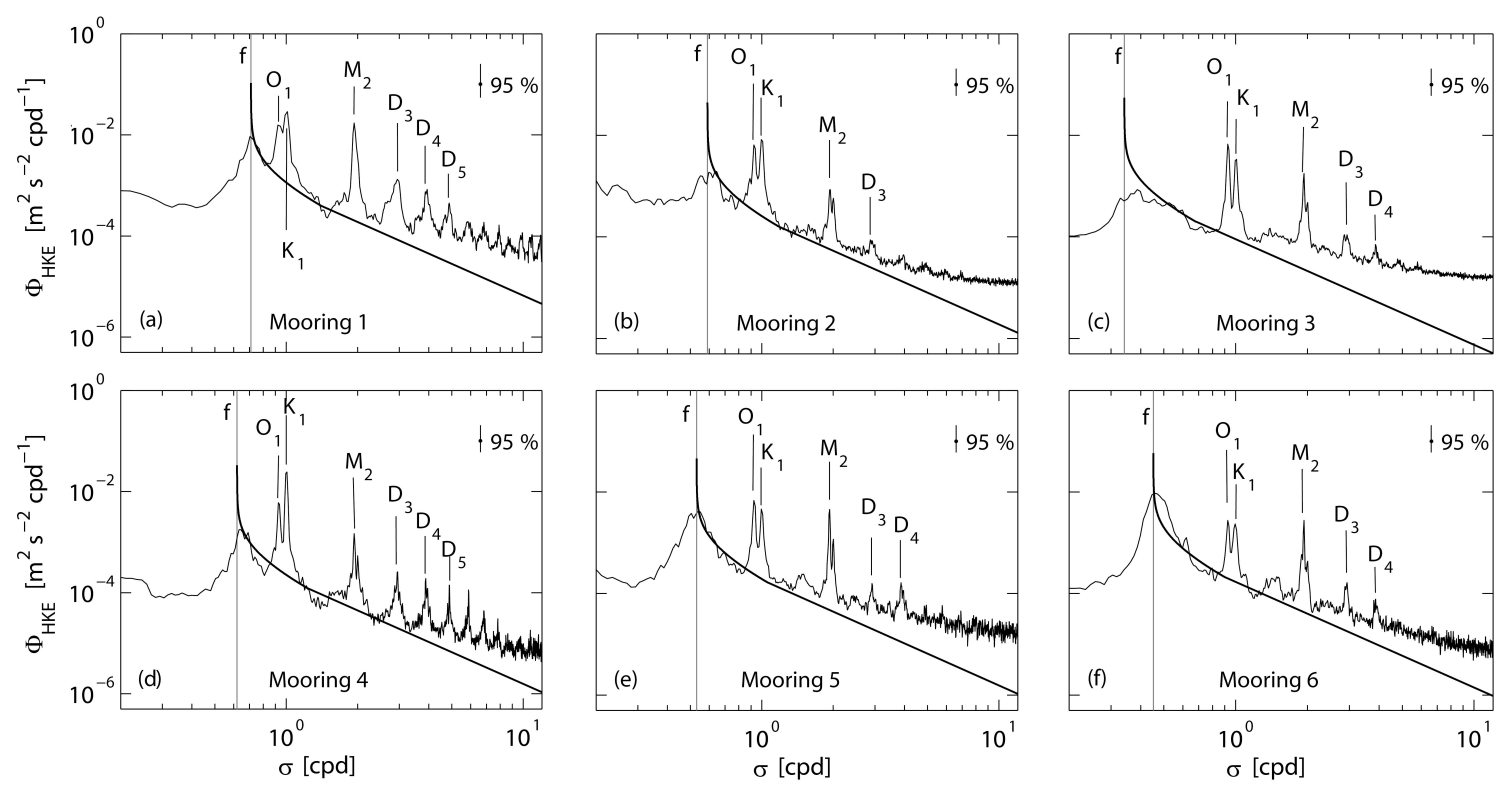

Figure 11. (a-f) Rotary spectra (clockwise plus counterclockwise) of horizontal kinetic energy for the six moorings deployed in the SCS $\left(1 \mathrm{cpd}=1\right.$ day $\left.^{-1}\right)$. Spectra are averaged over $z \in[60: 270] \mathrm{m}$. The canonical Garrett and Munk spectrum is shown for reference (smooth curve). The vertical lines represent various frequencies $\left(f, O_{1}, K_{1} \ldots\right)$. The $95 \%$ statistical significance level is indicated by the vertical bar in the upper-right corner.

bulent mixing in the water column. In regions $2-4$, the water column was characterized by weak shear and strong stratification. Shear was no longer sufficient to produce subcritical Richardson numbers and the turbulence was weak. The strong spatial correlation between high dissipation rates and strong shear presented in the thermocline in region 1 suggests that shear was one of the important drivers of the elevated turbulent mixing. The analysis of surface winds, internal waves, and barotropic tides indicates that the spatial distribution of turbulent mixing with elevated dissipation rates and diapycnal diffusivity concentrated in region 1 does not result from the measurement time or surface winds. The energetic internal waves and internal tides generated near the Luzon Strait are expected to make a dominant contribution to create this mixing pattern. Unfortunately, we have only one profile of microstructure measurement and short time series of current velocity obtained by the shipboard ADCP for each station; thus, it is impossible to separate the internal waves of various frequencies and explore their respective contributions to the dissipation. In order to resolve the internal waves in various frequencies, a long time series of fine-scale current velocities is required. We suggest further observations be done with frequent microstructure measurements and long time series of current velocity measurements to identify the dominant mixing mechanism in the northern SCS.

To predict realistic climate and circulation, mixing must be accurately represented in ocean models. Mapping of the dissipation rates throughout the ocean is a daunting task. However, this task can be made considerably easier if mixing can be estimated from more easily observed or modeled quan- tities, such as shear, stratification, and latitude. Two models (the GH model and MG model) were evaluated for parameterizing the dissipation rate in the SCS. Statistical analysis shows the dissipation in the SCS to be proportional to both the shear and buoyancy frequencies, in marked contrast to the predictions of the GH model, but consistent with the predictions of the MG model. The replication of the turbulence behavior greatly depends on the correct choice of model and appropriate tuning of the free parameters. The resolution of the shear and stratification is another factor in determining the success of models in parameterizing the turbulence (Palmer et al., 2013). Although the MG model can reproduce the dissipation in the SCS for our chosen vertical resolution $(16 \mathrm{~m})$, whether the distribution of the observed dissipation would change with finer resolution of shear and stratification is still an open problem. However, at least on the scale of internal waves $(16 \mathrm{~m})$, the MG model is clearly a better model than the $\mathrm{GH}$ model for the parameterization of turbulence in the upper ocean of the SCS, which provides a useful reference for modelers. Additional data with higher resolution are required to robustly fix this model in the near future.

Data availability. The research data can be accessed from the corresponding author Xiao-Dong Shang, whose email is xdshang@scsio.ac.cn. 
Author contributions. Xiao-Dong Shang and Gui-Ying Chen designed and carried out the experiments. Chang-Rong Liang prepared the manuscript with contributions from all co-authors.

Competing interests. The authors declare that they have no conflict of interest.

Acknowledgements. This work is supported by the National Natural Science Foundation of China: 41630970, 41376022, 41676022, and 41521005 . The data we used are from the South China Sea Institute of Oceanology.

Edited by: John M. Huthnance

Reviewed by: Hans Burchard and one anonymous referee

\section{References}

Alford, M. H., Peacock, T., MacKinnon, J. A., Nash, J. D., Buijsman, M. C., Centuroni, L. R., Chao, S. Y., Chang, M. H., Farmer, D. M., Fringer, O. B., Fu, K. H., Gallacher, P. C., Graber, H. C., Helfrich, K. R., Jachec, S. M., Jackson, C. R., Klymak, J. M., Ko, D. S., Jan, S., Johnston, T. M. S., Legg, S., Lee, I. H., Lien, R. C., Mercier, M. J., Moum, J. N., Musgrave, R., Park, J. H., Pickering, A. I., Pinkel, R., Rainville, L., Ramp, S. R., Rudnick, D. L., Sarkar, S., Scotti, A., Simmons, H. L., St Laurent, L. C., Venayagamoorthy, S. K., Wang, Y. H., Wang, J., Yang, Y. J., Paluszkiewicz, T., and Tang, T. Y.: The formation and fate of internal waves in the South China Sea, Nature, 521, 65-69, https://doi.org/10.1038/nature14399, 2015.

Brainerd, K. E. and Gregg, M. C.: Diurnal Restratification and Turbulence in the Oceanic Surface Mixed-Layer: 1. Observations, J. Geophys. Res.-Oceans, 98, 22645-22656, https://doi.org/10.1029/93jc02297, 1993.

Burchard, H. and Rippeth, T. P.: Generation of Bulk Shear Spikes in Shallow Stratified Tidal Seas, J. Phys. Oceanogr., 39, 969-985, 2009.

Carter, G. S. and Gregg, M. C.: Intense, variable mixing near the head of Monterey Submarine Canyon, J. Phys. Oceanogr., 32, 3145-3165, 2002.

Carter, G. S., Gregg, M. C., and Merrifield, M. A.: Flow and mixing around a small seamount on Kaena Ridge, Hawaii, J. Phys. Oceanogr., 36, 1036-1052, https://doi.org/10.1175/Jpo2924.1, 2006.

Chang, M. H., Lien, R. C., Tang, T. Y., D’Asaro, E. A., and Yang, Y. J.: Energy flux of nonlinear internal waves in northern South China Sea, Geophys. Res. Lett., 33, 155-170, https://doi.org/10.1029/2005GL025196, 2006.

Egbert, G. D. and Erofeeva, S. Y.: Efficient inverse modeling of barotropic ocean tides, J. Atmos. Ocean. Tech., 19, 183-204, 2002.

Garrett, C. and Munk, W.: Space-Time Scales of Internal Waves - Progress Report, J. Geophys. Res., 80, 291-297, https://doi.org/10.1029/Jc080i003p00291, 1975.

Gregg, M. C.: Scaling Turbulent Dissipation in the Thermocline, J. Geophys. Res.-Oceans, 94, 9686-9698, https://doi.org/10.1029/Jc094ic07p09686, 1989.
Gregg, M. C.: Estimation and geography of diapycnal mixing in the stratified ocean, Coast. Estuar. Stud., 54, 305-338, 1998.

Guo, C. and Chen, X.: A review of internal solitary wave dynamics in the northern South China Sea, Prog. Oceanogr., 121, 7-23, https://doi.org/10.1016/j.pocean.2013.04.002, 2014.

Henyey, F. S., Wright, J., and Flatte, S. M.: Energy and Action Flow through the Internal Wave Field - an Eikonal Approach, J. Geophys. Res.-Oceans, 91, 8487-8495, https://doi.org/10.1029/Jc091ic07p08487, 1986.

Holt, J. and Umlauf, L.: Modelling the tidal mixing fronts and seasonal stratification of the Northwest European Continental shelf, Cont. Shelf Res., 28, 887-903, 2008.

Huang, W., Johannessen, J., Alpers, W., Yang, J., and Gan, X.: Spatial and temporal variations of internal wave sea surface signatures in the northern South China Sea studied by spaceborne SAR imagery, in Proc. SeaSAR, Frascati, Italy, 21-25 January, 1-6, 2008.

Jing, Z. and $\mathrm{Wu}, \mathrm{L}$.: Seasonal variation of turbulent diapycnal mixing in the northwestern Pacific stirred by wind stress, Geophys. Res. Lett., 37, 137-139, 2010.

Klymak, J. M., Moum, J. N., Nash, J. D., Kunze, E., Girton, J. B., Carter, G. S., Lee, C. M., Sanford, T. B., and Gregg, M. C.: An estimate of tidal energy lost to turbulence at the Hawaiian Ridge, J. Phys. Oceanogr., 36, 1148-1164, https://doi.org/10.1175/Jpo2885.1, 2006a.

Klymak, J. M., Pinkel, R., Liu, C. T., Liu, A. K., and David, L.: Prototypical solitons in the South China Sea, Geophys. Res. Lett., 33, L11607, https://doi.org/10.1029/2006g1025932, 2006b.

Kunze, E. and Toole, J. M.: Tidally driven vorticity, diurnal shear, and turbulence atop Fieberling Seamount, J. Phys. Oceanogr., 27, 2663-2693, https://doi.org/10.1175/15200485(1997)027<2663:TDVDSA>2.0.CO;2, 1997.

Large, W. G. and Pond, S.: Open Ocean Momentum Flux Measurements in Moderate to Strong Winds, J. Phys. Oceanogr., 11, 324-336, https://doi.org/10.1175/15200485(1981)011<0324:Oomfmi>2.0.Co;2, 1981.

Laurent, L. S.: Turbulent dissipation on the margins of the South China Sea, Geophys. Res. Lett., 35, L23615, https://doi.org/10.1029/2008g1035520, 2008.

Ledwell, J. R., Montgomery, E. T., Polzin, K. L., St Laurent, L. C., Schmitt, R. W., and Toole, J. M.: Evidence for enhanced mixing over rough topography in the abyssal ocean, Nature, 403, 179182, https://doi.org/10.1038/35003164, 2000.

Lee, C. M., Kunze, E., Sanford, T. B., Nash, J. D., Merrifield, M. A., and Holloway, P. E.: Internal tides and turbulence along the $3000 \mathrm{~m}$ isobath of the Hawaiian Ridge, J. Phys. Oceanogr., 36, 1165-1183, https://doi.org/10.1175/Jpo2886.1, 2006.

Lien, R. C., Tang, T. Y., Chang, M. H., and D’Asaro, E. A.: Energy of nonlinear internal waves in the South China Sea, Geophys. Res. Lett., 32, L05615, https://doi.org/10.1029/2004GL022012, 2005.

Lien, R. C., Henyey, F., Ma, B., and Yang, Y. J.: Large-Amplitude Internal Solitary Waves Observed in the Northern South China Sea: Properties and Energetics, J. Phys. Oceanogr., 44, 10951115, https://doi.org/10.1175/Jpo-D-13-088.1, 2014.

Lozovatsky, I., Liu, Z., Fernando, H. J. S., Hu, J., and Wei, H.: The TKE dissipation rate in the northern South China Sea, Ocean Dynam., 63, 1189-1201, 2013. 
Lueck, R. G. and Mudge, T. D.: Topographically induced mixing around a shallow seamount, Science, 276, 1831-1833, https://doi.org/10.1126/science.276.5320.1831, 1997.

MacKinnon, J. A. and Gregg, M. C.: Mixing on the late-summer New England shelf - Solibores, shear, and stratification, J. Phys. Oceanogr., 33, 1476-1492, https://doi.org/10.1175/15200485(2003)033<1476:MOTLNE>2.0.CO;2, 2003a.

MacKinnon, J. A. and Gregg, M. C.: Shear and baroclinic energy flux on the summer New England shelf, J. Phys. Oceanogr., 33, 1462-1475, https://doi.org/10.1175/15200485(2003)033<1462:Sabefo >2.0.Co;2, 2003b.

MacKinnon, J. A. and Gregg, M. C.: Spring mixing: Turbulence and internal waves during restratification on the New England shelf, J. Phys. Oceanogr., 35, 2425-2443, https://doi.org/10.1175/Jpo2821.1, 2005.

Matsuno, T. and Wolk, F.: Observations of turbulent energy dissipation rate epsilon in the Japan Sea, Deep-Sea Res. Pt. II, 52, 1564-1579, https://doi.org/10.1016/j.dsr2.2004.06.037, 2005.

Matsuno, T., Shimizu, M., Morii, Y., Nishida, H., and Takaki, Y.: Measurements of the turbulent energy dissipation rate around the shelf break in the East China Sea, J. Oceanogr., 61, 1029-1037, https://doi.org/10.1007/s10872-006-0019-9, 2005.

Munk, W. H.: Abyssal recipes, paper presented at Deep Sea Research and Oceanographic Abstracts, Elsevier, 13, 707-730, 1966.

Nasmyth, P. W.: Oceanic turbulence, Retrospective Theses and Dissertations, 1919-2007, 1970.

Oakey, N. S.: Determination of the Rate of Dissipation of Turbulent Energy from Simultaneous Temperature and Velocity Shear Microstructure Measurements, J. Phys. Oceanogr., 12, 256-271, https://doi.org/10.1175/1520-0485(1982)012, 1982.

Osborn, T. R.: Estimates of the Local-Rate of Vertical Diffusion from Dissipation Measurements, J. Phys. Oceanogr., $\quad 10, \quad 83-89, \quad$ https://doi.org/10.1175/15200485(1980)010<0083:EOTLRO>2.0.CO;2, 1980.

Palmer, M. R., Rippeth, T. P., and Simpson, J. H.: An investigation of internal mixing in a seasonally stratified shelf sea, J. Geophys. Res.-Oceans, 113, C12005, https://doi.org/10.1029/2007jc004531, 2008.

Palmer, M. R., Polton, J. A., Inall, M. E., Rippeth, T. P., Green, J. A. M., Sharples, J., and Simpson, J. H.: Variable behavior in pycnocline mixing over shelf seas, Geophys. Res. Lett., 40, 161166, https://doi.org/10.1029/2012g1054638, 2013.

Peters, H. and Bokhorst, R.: Microstructure observations of turbulent mixing in a partially mixed estuary. Part I: Dissipation rate, J. Phys. Oceanogr., 30, 1232-1244, 2000.

Polzin, K. L., Toole, J. M., and Schmitt, R. W.: Finescale Parameterizations of Turbulent Dissipation, J. Phys. Oceanogr., 25, 306-328, https://doi.org/10.1175/15200485(1995)025<0306:FPOTD>2.0.CO;2, 1995.

$\mathrm{Qu}, \mathrm{T}$., Mitsudera, H., and Yamagata, T.: Intrusion of the North Pacific waters into the South China Sea, J. Geophys. Res.-Oceans, 105, 6415-6424, https://doi.org/10.1029/1999jc900323, 2000.

Ramp, S. R., Tang, T. Y., Duda, T. F., Lynch, J. F., Liu, A. K., Chiu, C. S., Bahr, F. L., Kim, H. R., and Yang, Y. J.: Internal solitons in the northeastern South China Sea. Part I: Sources and deep water propagation, IEEE J. Oceanic Eng., 29, 1157-1181, https://doi.org/10.1109/JOE.2004.840839, 2004.
Rice, J. A.: Mathematical Statistics and Data Analysis, Nelson Education, 421-425, 2006.

Rippeth, T. P.: Mixing in seasonally stratified shelf seas: a shifting paradigm, Philosophical Transactions, 363, 2837, 2005.

Saenko, O. A. and Merryfield, W. J.: On the effect of topographically enhanced mixing on the global ocean circulation, J. Phys. Oceanogr., 35, 826-834, https://doi.org/10.1175/Jpo2722.1, 2005.

Sandstrom, H. and Elliott, J. A.: Internal Tide and Solitons on the Scotian Shelf - a Nutrient Pump at Work, J. Geophys. Res.-Oceans, 89, 6415-6426, https://doi.org/10.1029/Jc089ic04p06415, 1984.

Shaw, P. T.: The Seasonal-Variation of the Intrusion of the Philippine Sea-Water into the South China Sea, J. Geophys. Res.Oceans, 96, 821-827, https://doi.org/10.1029/90jc02367, 1991.

Shay, T. J. and Gregg, M. C.: Convectively Driven Turbulent Mixing in the Upper Ocean, J. Phys. Oceanogr., 16, 1777-1798, https://doi.org/10.1175/15200485(1986)016<1777:Cdtmit>2.0.Co;2, 1986.

Simpson, J. H. and Bowers, D.: Models of stratification and frontal movement in shelf seas, Deep-Sea Res. Pt. I, 28, 727-738, 1981

Tian, J. W., Yang, Q. X., and Zhao, W.: Enhanced Diapycnal Mixing in the South China Sea, J. Phys. Oceanogr., 39, 3191-3203, https://doi.org/10.1175/2009jpo3899.1, 2009.

Tsujino, H., Hasumi, H., and Suginohara, N.: Deep Pacific Circulation Controlled by Vertical Diffusivity at the Lower Thermocline Depths, J. Phys. Oceanogr., 30, 2853-2865, 2000.

van der Lee, E. M. and Umlauf, L.: Internal wave mixing in the Baltic Sea: Near-inertial waves in the absence of tides, J. Geophys. Res.-Oceans, 116, C10016, https://doi.org/10.1029/2011jc007072, 2011.

van Haren, H.: On the polarization of oscillatory currents in the Bay of Biscay, J. Geophys. Res.-Oceans, 108, 3290, https://doi.org/10.1029/2002jc001736, 2003.

van Haren, H., Maas, L., and van Aken, H.: On the nature of internal wave spectra near a continental slope, Geophys. Res. Lett., 29, 1615, https://doi.org/10.1029/2001g1014341, 2002.

Wijesekera, H., Padman, L., Dillon, T., Levine, M., Paulson, C., and Pinkel, R.: The Application of Internal-Wave Dissipation Models to a Region of Strong Mixing, J. Phys. Oceanogr., 23, 269-286, 1993.

Wolk, F., Yamazaki, H., Seuront, L., and Lueck, R. G.: A new free-fall profiler for measuring biophysical microstructure, J. Atmos. Ocean. Tech., 19, 780-793, https://doi.org/10.1175/15200426(2002)019<0780:ANFFPF>2.0.CO;2, 2002.

Wu, C. R. and Hsin, Y. C.: The forcing mechanism leading to the Kuroshio intrusion into the South China Sea, J. Geophys. Res.Oceans, 117, 9, https://doi.org/10.1029/2012jc007968, 2012.

Wu, L. X., Jing, Z., Riser, S., and Visbeck, M.: Seasonal and spatial variations of Southern Ocean diapycnal mixing from Argo profiling floats, Nat. Geosci., 4, 363-366, https://doi.org/10.1038/Ngeo1156, 2011.

Xie, X. H., Shang, X. D., and Chen, G. Y.: Nonlinear interactions among internal tidal waves in the northeastern South China Sea, Chin. J. Oceanol. Limn., 28, 996-1001, https://doi.org/10.1007/s00343-010-9064-8, 2010.

Xie, X. H., Cuypers, Y., Bouruet-Aubertot, P., Ferron, B., Pichon, A., Lourenco, A., and Cortes, N.: Large-amplitude internal tides, solitary waves, and turbulence in the cen- 
tral Bay of Biscay, Geophys. Res. Lett., 40, 2748-2754, https://doi.org/10.1002/Grl.50533, 2013.

Yang, Q. X., Tian, J. W., Zhao, W., Liang, X. F., and Zhou, L.: Observations of turbulence on the shelf and slope of northern South China Sea, Deep-Sea Res. Pt. I, 87, 43-52, https://doi.org/10.1016/j.dsr. 2014.02.006, 2014.

Yang, Q. X., Zhao, W., Liang, X., and Tian, J.: Three-Dimensional Distribution of Turbulent Mixing in the South China Sea, J. Phys. Oceanogr., 46, 769-788, https://doi.org/10.1175/JPO-D14-0220.1, 2016.

Yang, Y. J., Fang, Y. C., Chang, M. H., Ramp, S. R., Kao, C. C., and Tang, T. Y.: Observations of second baroclinic mode internal solitary waves on the continental slope of the northern South China Sea, J. Geophys. Res.-Oceans, 114, C10003, https://doi.org/10.1029/2009jc005318, 2009.
Zhao, Z. X.: Internal tide radiation from the Luzon Strait, J. Geophys. Res.-Oceans, 119, 5434-5448, https://doi.org/10.1002/2014JC010014, 2014.

Zhao, Z. X., Klemas, V., Zheng, Q. N., and Yan, X. H.: Remote sensing evidence for baroclinic tide origin of internal solitary waves in the northeastern South China Sea, Geophys. Res. Lett., 31, L06302, https://doi.org/10.1029/2003g1019077, 2004. 